\title{
A Hybrid Control Chart-Taguchi Method for Control and Optimization of Safety Conformity
}

\author{
S.A. Martins and S.A. Oke*
}

\begin{abstract}
In this paper, a hybrid control chart-Taguchi method (CCTM) is proposed to solve the control and optimization problem regarding safety conformity parameters for a bottling process plant (BPP). The CCTM fuses the conservative control charts, which monitor the safety conformity parameters to promote and maintain the uppermost grade of employees' physical, social and mental well-being. The control chart result is placed in the Taguchi methodical phase of factor-level determination to cultivate an orthogonal array. Then, the inventive rational ability of the control chart is used to correct the process and hence, enhances the Taguchi method. Consequently, the CCTM can be intensely robust and statistically precise. The proposed CCTM was successfully used to solve the safety conformity problem involving the control and parametric optimization in a bottling process plant. The field data uncovers the ability of the proposed CCTM to control and optimize the bottling process plant parameters. Moreover, it showcases the results as better than an enormously stronger than the conventional Taguchi method.
\end{abstract}

Keywords: Taguchi method, control chart, orthogonal array, bottling plant.

Article Info: Received October 30, 2020; Revised January 23, 2021; Accepted July 1, 2021.

\section{INTRODUCTION}

The objective of this paper was to establish a hybrid control chart-Taguchi method (CCTM) to solve the control and optimization problem regarding safety conformity parameters for a bottling process plant (BPP). However, the BPP is compelled to guarantee the safety and conformity of the work segments with respect to the use of personal protectives, machine guards, and other safety devices (Pichard et al., 2017; Geraci et al., 2018; Kalashnikov and Sakrutina, 2019; Cheng et al., 2019). Consequently, the present laws on process integrity must be respected while the good safety anticipations of the populace must be satisfied (Grob et al., 2009; Grob and Marmiroli, 2009; Abdellah et al., 2015; Brhlikova et al., 2015). If operations are clearly unsafe in the plant or deviate significantly from the legal obligations, the process engineer is required to initiate the essential engagements (Vukicevic et al., 2019; Baldissone et al., 2019).
Certainly, safety monitoring and conformance models have been reported with substantial efforts over the past decades (Oke et al., 2005; Lüken et al., 2006; Oke et al., 2006; Ayomoh and Oke, 2006; Mewes et al., 2011; Ruff et al., 2011; Yamin et al., 2014; Parker et al., 2015a; Parker et al., 2015b; Dźwiarek and Latała, 2016). Notwithstanding, it is comprehensible that none of the models discussed by these early researchers openly incorporates the concerns of bottling process plants in their evaluation procedures. Furthermore, the results of these techniques are not articulated to reveal the total performance of the workers in terms of keeping strict compliance with the company's regulations on safety (Lüken et al., 2006; Mewes et al., 2011; Ruff et al., 2011; Yamin et al., 2014; Parker et al., 2015a; Parker et al., 2015b; Dźwiarek and Latała, 2016). Recently, a new inclination is built covering the concept of safety conformity in bottling plants with a recent contribution by Uzor and Oke (2018) and lately, the report by Martins and Oke (2020). However, this initiative, while

\footnotetext{
S.A. Oke* is with the Department of Mechanical Engineering, University of Lagos, Nigeria (email: sa_oke@yahoo.com).

* Corresponding author
} 
worthwhile, has its flaws. The first article focused on machine guards alone, while the second article centered on optimization using the Taguchi method alone.

However, machine guards are a few of the important bottling plant components for assessment, but nonmachine-related activities are also important (i.e., Forklift driving, stockroom activities, and sewage treatment activities) (Martins and Oke, 2020); conversely, they were ignored in the first article. While the second article incorporates these activities, the control aspect is missing in the model (Martins and Oke, 2020). Nevertheless, control is a fundamental issue for the proper adherence to safety rules in the bottling plant (Riera et al., 2014; Hong et al., 2018; Wikner et al., 2019). Moreover, installing a control mechanism in the safety conformity model may account for enhanced compliance, lessened safety cost, and elevated profitability in the plant. Furthermore, it is possible to establish the causes of non-conformance and the point where action should be taken.

This paper contests the newly-recognized idea of the prediction of safety conformity in a bottling process plant to create a new analysis within the safety engineering context. This new analysis transforms the prevalent set of ideas in control chart theory from the quality management literature to reinforce a comparatively ignored perspective within safety engineering. Thus, the following describes the statement of the problem for this study. In the bottling process plant, the safety scenario has changed (more personal protective equipment such as items for eye protection, safety helmets, elevated visibility clothing, gloves, safety harnesses, and safety footwear are provided by the plant). There is a necessity to have an understandable technique for evaluating the compliance stage of all the employees in the organization. It will be utilized to understand the degree of their usage by all employees of the organization. It is not sufficient to use protective equipment only while working with specific machines but at all times when required to be put on. This will make the employees work successfully, offer superior maintenance services to all its internal customers, and avoid accidents and litigation costs. The problem is a further complication as there is no way to know when the operator or maintenance personnel is not conforming to the safety guidelines and out of control. This is the stage where corrective actions need to be exercised. Furthermore, it is not known which of the factors is more important than the others. This will make it extremely difficult to avoid accidents.

Besides, several workers in the global bottling plants suffer from accidents yearly due to non-conformance to safety guidelines and regulations at various workstations or operation centers. Expectedly, this figure may rise as the scenario becomes complicated by the increasing and urbanizing populace joining a growing demand for bottled soft drinks. These are placing new pressures on the bottling process plant equipment and facilities, and capacities are expected to expand soon. As the world has a projected population increase in the next few years, there is an urgent necessity to establish novel and innovative techniques of control and optimization to tackle the safety behavior and culture of the expansive body of workers to use the projected and expanded bottling equipment and facilities.

This paper contributes to the safety engineering and occupational safety literature by:

1) Emphasizing optimization and control parameters undecided in previous safety conformity analysis that could strengthen the understanding of scholars on the optimization and control parameters and method to observe.

2) Executing the control chart theory and the theory guiding Taguchi method that could stimulate new logic and improvement of the current thoughts in optimizing and the control of safety conformity

3) Instituting research imperfections of safety conformity to situate innovative research exploration appropriately

\section{LITERATURE REVIEW}

\subsection{General}

Among manufacturing issues threatening the sustainability and economy of the bottling plant, safety concerns, particularly, safety conformity comes to the fore owing to its distinctive attributes and what its negative aspects could lead to. For instance, unsafe situations could lead to injury or loss of lives. Safety conformity is known as a major control criterion, which helps the bottling plant to maintain good health status. As the literature was analyzed, it was noted that in many safety works of literature, safety (mechanical) guards are examined in some studies (Meves et al., 2011; Yamen et al., 2014; Parker et al., 2015a; Parker et al., 2015b; Uzor and Oke, 2018). Approximately all these investigators used the machines at the production floor as the lens of analysis and discussion (Yamin et al., 2014; Uzor and Oke, 2018).

In contrast to these research reports, the addition of non-production-centered activities is investigated in the current research inquiry because of the advantages of companywide studies over sectional studies, corporate commitment toward achieving organizational goals, overall cost-cutting, and enhanced safety culture company-wide. Besides, it has been noted that safety activity levels impact conformance accomplishment in the company's wide range of analyses of safety conformity (Martins and Oke, 2020). Based on this information, the whole industrial segments were chosen as the target in this research since it is considerate that it will be a superior approach to understanding the safety conformity in the bottling process plant. In Martins and Oke (2020), a multiple regression approach was adopted to evaluate the safety conformity of the company-wide segments. However, this paper discusses a new model and a hybrid control chart fused with the Taguchi method. Landi et al. (2018) outlined the candidate material models for FEM testing considering non-alloy steel materials and a simulation study of sheets impact for safety guards design. They correlated experimental information with numerical tests to confirm the potential to apply reliability testing measures. 


\subsection{Control charts in safety research}

A control chart was instituted in this paper to establish if the safety conformity process is in control or not. To be in control, all the monthly values of safety conformity measured will be spread or clustered at certain areas within the upper and lower control limits. However, when points (monthly safety conformity values) are outside these two boundaries, the bottling process safety conformity is outside control. The control chart aids in establishing the possible causes of safety conformity performance variations. In general, the types of variable control charts available are the $\mathrm{X}$ bar and $\mathrm{R}$ chart, $\mathrm{X}$ bar, and $\mathrm{S}$ chart, MA-MR chart, and target charts. In a certain work setting, the name control charts may be missing but replaced with process behavior charts or the Stewart charts.

The name "X bar and $\mathrm{R}$ chart" is used in this work, which tracks the subgroup average and the subgroup range. The $\mathrm{X}$ bar and $\mathrm{R}$ chart are adopted in the present paper on the assumption that the safety conformity process changes fast. It tests quickly and is not expensive to implement. Notwithstanding its benefit of ease of usage, the $\mathrm{R}$ chart component of the control chart has a shortcoming of not tracking the variation within the whole process over time. However, if the $\mathrm{R}$ chart gives an out-of-control result, the implication is that a measurement system problem exists or process equipment failure emerges.

Although the literature reveals the feasibility of applying control charts to safety practices as demonstrated in Schuh-Renner et al. (2013) and Papic and Pantelic (2014), such novel applications to control adherence of works to safety rules through safety conformity evaluation in a bottling plant is missing. The details of the mentioned control chart application articles in safety practices are as follows. Papic and Pantelic (2014) proposed a novel safety-oriented maintenance idea based on the deployment of FMECA and a safety control chart to establish the worst primary occurrence. A novel safety evaluation adoption scheme during the systems functioning phases, considering the accident situation modeling, was indicated. SchuhRenner et al. (2013) employed the cumulative sum (CUSUM) control charts using historical facts and weighed the outcome of using the exponential CUSUM (time-between-events) against the Poisson CUSUM with an example that revealed the condensed time of accumulation and time-between-events.

\subsection{Taguchi method in safety research}

Taguchi method is a quality engineering method applied to the safety conformity process in the bottling plant through process optimization to enhance the quality of safety practices and reduce the cost associated with variations in safety conformity. As the technique is systematic, it has the attribute of limiting the number of time wastage for tests, leading to accident cost savings. Since the loss function of the Taguchi method established has the deviation of a safety conformity value from the perfect state of $100 \%$, it monitors noise, which is often attributed to this variation. The work by Alharthi and Yang (2014) validated the application of the Taguchi method in safety practices. They analyzed the response of the influence of control variable, namely response to alarm, training, age experience, and qualification on the proportion of damage and extinguishing time in an experiment based on the use of an extinguisher in fire control. Based on an L16 orthogonal design, training and experience were chosen to influence the percent damage and extinguishing time largely.

Sii et al. (2001) deployed Taguchi principles to maritime safety and illustrated the approach with an example regarding the determination of risk for ships to establish insurance rates. Azadeh and Sheikhalishahi (2015) introduced the idea of the Taguchi scheme to achieve utmost performance in safety, health, environment, and ergonomics in generation companies (GENCOs). It was concluded that the approach help to drive continuous enhancement of performance in GENCOs when supplying energy regarding the health, safety, agronomies, and environmental factors.

\section{METHODOLOGY}

The idea of fusing a control chart with the Taguchi method is novel. This was confirmed from the literature review. However, only one paper was found to be relevant to the current paper (Martins and Oke, 2020). As its principal focus, Martins and Oke (2020) created a new viewpoint to safety conformity evaluation by arguing that safety conformity had been limited to machine guarding evaluation perspective. By extending safety to non-production-related services such as engineering workshop activities for forklift safety compliance, Martins and Oke (2020) seem to have expanded the scope of safety conformity evaluation. While the paper produced a predictive model based on multiple regression analysis, the present paper proposes a divergent path to propose how the safety conformity attribute in workers can be controlled and optimized concurrently. This model helps the worker create and adopt a positive attitude to safety conformity after the loss of consciousness that safety principles only adhere to moments after an accident happens. Everybody is more careful or when supervisors are around, checking for workers' compliance at their workstations.

\subsection{Description of critical aspects of the bottling company}

In this article, some case details are presented concerning a bottling process plant operating in the southwestern part of Nigeria to approve the method introduced in this study. For the purpose of instituting the safety conformity model proposed here, the organization was divided into five segments: stockroom, beverage testing unit, suppliers, vehicle fleet flotilla, and manufacturing hallway. This classification was 
informed by the suggestion in Martins and Oke (2020) that argued and used verified data to confirm that the previous literature conception of safety conformity was limited to mechanical guards alone and needs adjustments (Uzor and Oke, 2018).

In the five segments discussed, only two segments are production-related: stockroom and the manufacturing hallway. In the system studied, the stockroom was conceived differently from the conventional store where goods are kept. It extends to goods storage as well as a manufacturing plant that produces soft drinks. In essence, more than a production line is maintained in the plant. The old line often runs with bottles (glass) since the machines are still operating for profit. A new line is also used with plastic bottles. Both lines are separately maintained by the central maintenance team. However, the total productive maintenance concept is operated within the plant such that the machine operators are empowered to do minor repairs, which often will get the machines transformed to the functioning condition.

Moreover, if the fault on the machine is above the technical knowledge of the operator that has undergone the total productive maintenance training, maintenance experts from the central maintenance unit are called for intervention. Each of the mentioned five segments consists of different worker groups with separate goals but all aligned with the goal of the bottling plant. Some details about the segments are given in this section.

Beverage testing unit: This type of unit principally focuses on the quality assurance aspects of soft drinks. The BTU was instituted to avoid mistakes and defects in soft drinks; it is backed up by the ISO 9000 that offers assurance that the quality needs will be attained. The quality aspects of the soft drinks include freshness, taste, filling height, color, smell, and possibility of defects on the bottle. The position of this unit relative to the production process is the post-production position after which the beverage has been produced and is being inspected for quality. The BTU contains five groups of workers. The first is the sugar lifters saddled with the responsibility of transferring the sugar compartments from the stone to the mixing sites. In the food industry, stringent conditions are placed on the handling of food items since any contamination of the food items from the source could affect the whole production lot. As such, the sugar handlers are expected to maintain the highest level of hygiene and at all times wear gloves, and protective both for the nose and mouth (masks) and the overall must be maintained neatly.

The syrup mixers are the second group within the beverage testing unit segment. They are to mix the sugar with other ingredients to make the syrup pumped to the filling machine within the plant. Meanwhile, laboratory technicians, another group of workers under the BTU, must carry out tests on syrup after the sugar is mixed with water and other ingredients. Laboratory technicians carry out chemical tests to ascertain the levels of the chemical properties of the mixed syrup against the standard established. They must also comply with wearing all the necessary protective wears while at work. The water treatment technicians are responsible for the treatment of raw supplied water with chemicals to control its hardness and make it tasteless in the natural form and also odorless. In doing so, chemicals may be inhaled without due mask usage, which should be avoided. The ETP technicians are responsible for the electronic control of the filler and are links from the syrup mixing section to the filling machine to where the syrup is channeled. There may be other support staff. In all, every staff in this section has the responsibility of using masks and nose covers.

Suppliers: Suppliers mainly consist of three groups: The security, kitchen, and suppliers. Security has a regulatory influence on those coming in and out of the company. Apart, their personal responsibility is to use protective masks in hazardous areas where materials are protected against pilferage and damage. An important aspect of safety is the use of seat belts by drivers into and outside the organization; without the approval of the security personnel people cannot be allowed into the factory without protective and the use of seat belts. If this is not followed, the security team is counted as nonconforming to set standards of safety conformity. For the kitchen personnel, hygiene is a compulsory requirement as a staff is expected to cover their heads with covers and mask to cover nose while preparing food for the company staff. Conformity and nonconformity may be assessed without prior notice to the staff. There are other duties in which suppliers are permitted to hold, including the sweeping and cleaning of the company's premises. While doing these, noses need to be covered against the inhalation of dust and foul odors in hazardous environments such as the gas storage area.

Vehicle fleet flotilla: The vehicle fleet flotilla segment has three groups of technicians that are assessed for safety conformity. The first is the forklift technicians who maintain all the forklifts used for cargo handling. In achieving their objectives, repairs are made under the circumstance of safety. A simple rule, for instance, is not to engage in repairs when the forklift engine is still functioning. Violation of this rule may result in accidents. There are several other rules which are similar to these that are binding on vehicle repairs technicians. These rules must be adhered to for an accident-free work environment. The second group within the vehicle fleet flotilla segment is the welders. They work together with the forklift technicians, but their welding machines and resources also have safety hazards that should be identified and eliminated during work. The several hazards of the welder may include the harsh light from the welding machine and how it could cause harm to the user and people in the environment. The wearing of safety booths in the cause of lifting heavy objects for welding is of utmost interest. Furthermore, the welding shields and masks should be worn during welding. The battery chargers and technicians are the last groups who are saddled with the responsibility of maintaining the battery. Several hazards are also involved in the work, and such should be presented.

Manufacturing hallway: The jobs in this section involve carrying (front carry roughly 25 foot carry up), 
pulling/pulling (chemical barrels and scrubbing), ambulatory activity (standing, stairs, climbing, and walking), squatting/kneeling/stooping, repetitive grasping/use of hand, reaching). The forklift operator (forklift truck driver) operates and manages industrial trucks. The responsibility includes moving, loading, unloading, and delivering materials around the stockroom and outside the stockroom, such as storage yards. Often the forklift operator work involves loading and unloading trailers and coupled with other material handling equipment. The forklift safety is primarily charged to the operator, who is expected to exercise the greatest care handling the forklift truck. There are two primary checks that the forklift operator is accountable for: visual and operational. In visual checks, some questions that must be answered are whether the headlights and brake lights are in working conditions. Is the load being carried exceeding the maximum load value? Are my batteries secured? Is the chain attached to the forklift truck tight and lubricated? Do we have any damages that are visible in the forklift truck? Are my tires worn out or flat? Do we have signs of leakages of anything or smells produced by the forklift? The operational checks involve checks on the horn, hydraulic system, fuel system, and brake. Such questions to be answered include whether my brakes are working well. For the backup warming, the concern is whether it can be heard. When fueling the forklift, do I often turn it off? Are all the hydraulic movements okay? Are the motions of the truck in the forward and reverse order okay? Are the horns working correctly?

The filler operator is responsible for filling the bottles with the prepared syrup mixture and ensure it is working; the operator supervises the filler. The filler should run functionally and safely. The filler fills and fastens unfilled containers with syrup mixture. The packer places the ultimately filled bottles into the container for onward movement to the stock yard. The operator (utilities) is often concerned with the $\mathrm{CO} 2$ cylinders and is responsible for filling the unfilled cylinders. The palletizer is accountable for palletizing full case bottled drinks - also, a depalletizer depalletizes empty pallets of bottles or cans. The washer operator is accountable for pre-mixing activities, including opening, washing, and filling the pre-mix canisters. These positions are prone to moving machinery like forklifts and production equipment), loud noise, dust, and extreme temperature. Safety protection devices such as masks and ear mufflers need to be worn all the time in those hazardous places.

Stockroom: The idea of a stockroom in the organization studied is one that produces soft drinks, stores them, and receives from other locations within the region to store since it is closer to the wholesalers than direct transportation of the truck-containing goods from Interland straight to the wholesalers. With this idea, the total cost of transportation is reduced. It should be noted that since the products from other plants to the warehouse are not directly released to the wholesalers, the logistics of the products may be planned during offroad traffic periods of the day. For example, midnight to reduce fuel wastage, labor hours wastage on the road, traffic frustration, and the overall transportation cost and efforts are reduced. Another metric of performance that justifies the siting of a warehouse is the savings in carbon dioxide emissions from vehicles in a year as a result of reduced travel times by the trucks. During the day, longer travels are envisaged, thus increasing the carbon dioxide emissions into the atmosphere. This is called the reduction of carbon footprint by heavy goods vehicles conveying the drinks. Often the warehouse has a goal of reducing the carbon footprint regarding the drink conveyance per year. The total responsibility of the plan involves the management of primary materials, materials to fill drink and snack machines, finished goods, uniforms for staff, and the marketing of materials to other plants.

Considering the various aspects of the bottling process plant mentioned, a novel model is being built up in the current article for effective control (and detection of an out-of-control situation for workers not complying with the safety rules) and the concurrent optimization of safety conformity factors. The innovative deployment of integrated control charts (X bar and $\mathrm{R}$ chart) and the Taguchi method removes the issue of safety failure and non-conformity of workers to safety rules in the bottling process plants.

In optimizing the process parameters of a system using the Taguchi method, analysis is commenced with the establishment of the factors and levels. However, to move forward, the goal of the system must be defined and the goal criterion introduced to the evaluation of the signal-to-noise ratio. This ratio of the strength for the signal (outcome of the system) to the noise (distractions entertained by the system) is determined by the goal values of the system, which should fall into any of the three criteria of smaller is better, larger is better and nominal the best. To illustrate the three criteria with examples, the following may be useful. The smaller, the better may be best illustrated by the example of nonconforming soft drinks produced by the machine. Since the goal is to achieve zero non-conformity, the higher values of non-conformities are undesirable, and the choice of smaller the better fit this situation. To illustrate, the more considerable, the better criterion, consider the health of the machines producing the soft drinks. Prolonged work hours with the machine hours get enlarged with the machine utilization is desired. Thus, as the machine hours get enlarged, the larger the system proposed better regarding the goal. For the nominal, the best criterion, lubricating the essential parts of the machine, is a good illustration. Here adding excessive lubricants to the machine is a waste and may trigger unwarranted temperature rise if the lubricant gets to a hot part of the machine.

Moreover, too little of the lubricant may cause the machine to lock and cease to function. For the problem being solved in this article concerning safety 
conformity, it is desirable to have higher values of conformity. The larger, the better criterion is of interest to the analyst.

\subsection{The hybrid model}

In safety conformity endeavors, the organization is interested in deploying the best tools that will have the most important impacts on the safety culture and safety performance of the organization. However, most organizations are incapable of detecting when the operator or employees of the organization are engaging in activities outside the defined boundaries. In this case, they are described to be out of control. The goal is to utilize control charts ( $\mathrm{X}$ bar and $\mathrm{R}$ chart) to establish if the process of safety conformity is steady. The $\mathrm{X}$ bar diagram reveals how the mean of the safety conformity parametric values adjusts ultimately. However, the $\mathrm{R}$ chart discloses how the array of the subgroup for the safety conformity parameters alters eventually. To obtain values for the control charts, the values from the operational activities, where compliance and noncompliance activities are observed and recorded, are used. On a monthly basis, a walk-through visit of important locations is made, and a record of activity at that instance is taken. For instance, if the machine operator is supposed to use the gear box cover but refuses to fix it because it often breaks down and it is convenient to remove it to avoid the incurred setup time to remove it, it is taken as a non-compliant activity. Otherwise, the operator is compliant.

Having obtained the values for a month, a monthly average is obtained by dividing the value by the total number of visits and observations in the month. These monthly averages are then obtained for the whole year. For the X-bar computation, the average for the conformity is taken. The difference between the highest and lowest values is the range, and this is computed for all the data points within the month. An average of these values yields the $\mathrm{R}$ bar. It is essential to compute the values of the control chart variables and use them for judgment because of the benefit to the bottling plant. These values are the key tools to lower nonconformance to standards among employees, which translates to lower expenses. Of course, gain in operational efficiency may be obtained with this as the consciousness of the workers alone that their performance is being evaluated leads to doing the right thing; the use of safety conformity kits and facilities.

After obtaining values for the control charts, the hybrid control chart Taguchi method (CCTM) is fused into the Taguchi method. This monitors the safety conformity parameters to promote and maintain the uppermost grade of employees' physical, social and mental well-being. Taguchi technique will be employed in device experiments to understand how the various safety conformity parameters influence the average values and the accomplishment feature of the process's variance, which describes how healthy the process operates. The control chart's outcome is placed into the Taguchi methodical phase of the factor-level determination to cultivate an orthogonal array. Then, the inventive rational ability of the control chart is used to correct the process and hence, enhances the Taguchi technique. The hybrid CCTM is a new idea searching for improved company safety conformity practices and augments the quality of well-being of the bottling plant workers. This aims to expand the worker's health status from the perspectives of social, physical, and mental performance at work. The methodology for the work is shown in Figure 1.

The methodology adopted in the research is declared in steps are follows:

Literature review: In search of a safety conformity problem with the unique blend of engineering theory and managerial relevance

Field visit to an organization: Discussion with workers and management and the gathering of data

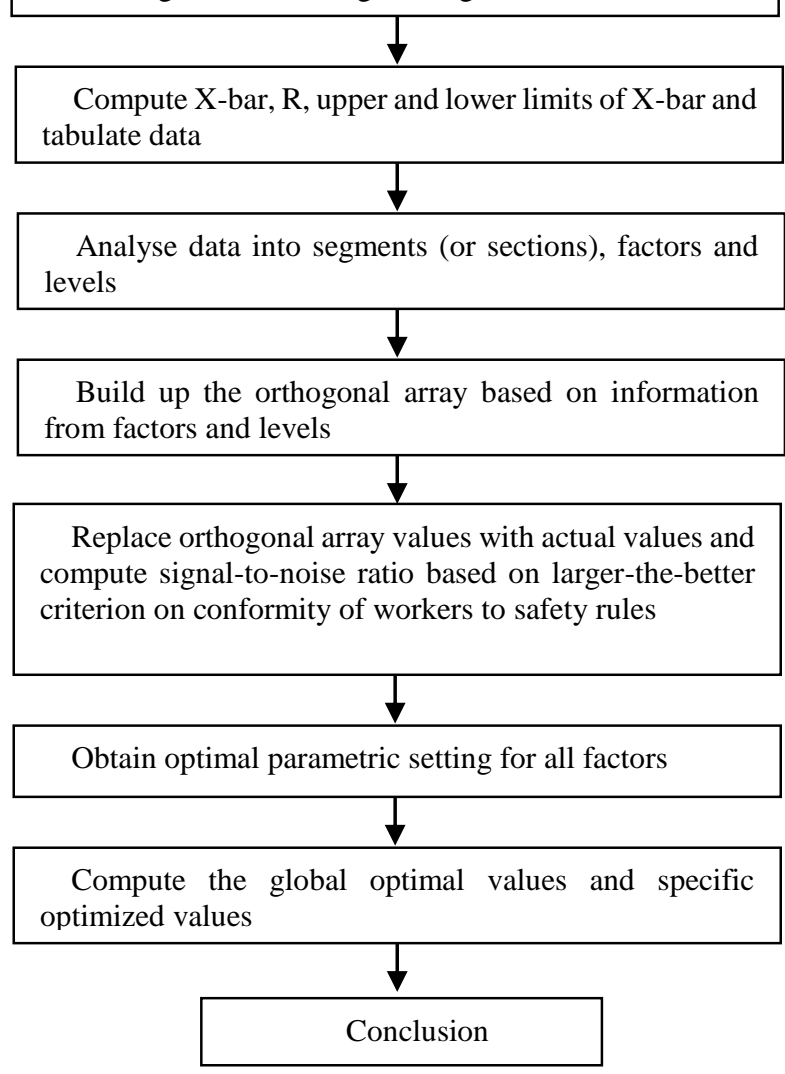

Figure 1. Methodology for X-bar and R chart' Motivated Taguchi Method

Steps were taken in the 'X-bar and $\mathrm{R}$ chart' Motivated Taguchi Method. The detailed procedure for the introduced method is as follows:

The procedure taken in the 'X-bar and $\mathrm{R}$ chart' Motivated Taguchi Method is outlined step by step below.

Step 1: Congregate data to be examined and tabulate.

Step 2: $\quad$ Prepare the X-bar, R chart, upper and lower limits of X-bar, and R chart for the data; 
consider the average regarding the $\mathrm{R}$ chart and tabulate.

Step 3: Cluster data into system segments, develop levels for the factors.

Step 4: Establish and examine the levels in each factor.

Step 5: Develop an orthogonal array using Minitab 16 statistical software (with levels and factors as the determining parameters).

Step 6: Substitute the actual values for the levels into the orthogonal array.

Step 7: Calculate the signal to noise ratio using the orthogonal array.

Step 8: Generate the signal to noise response table (using the average of the signal to noise ratio at every level).

Step 9: Get the optimal parametric setting from the signal to a noise response table.

Step 10: Calculate the optimized global value.

Step 11: Calculate the specific optimized value (i.e., the average of optimized global value).

\section{RESULTS AND DISCUSSIONS}

The results are presented in this section with the associated discussions.

Step 1: Gather data to be analyzed (Table 1).

Step 2: Calculate the X-bar, $\mathrm{R}$, upper and lower limits of $\mathrm{X}$-bar and $\mathrm{R}$ respectively for the data, take the average in the case of $\mathrm{R}$ and tabulate

The following explanations may be helpful to understand how to measure the $\mathrm{X}$ bar and $\mathrm{R}$ chart for every factor in the safety conformity evaluation process. The $\mathrm{X}$ bar is an indicator for the sample mean for a set of conformity data that approximates the exact population factor. In trying to understand the exact population factor, $\mathrm{N}$, which is the number of data points, is set at 12 , the period of twelve months over which conformity data was collected from the bottling process plant. Consider the forklift drivers in the stockroom section of the plant. The original conformity collected from the first to the twelfth month is $100,100,100,100$, $100,92.31,100,100,100,100,100$, and 100, respectively. To calculate the $\mathrm{X}$ bar, it is mandatory to obtain the average of all the X's as $1192.31 / 12$, obtained as 99.36, denoted as the $\mathrm{X}$ bar. This is sometimes referred to as the centerline or process location. To actualize a control chart computation, two points are placed equidistant from this X bar, the UCL and LCL, respectively, referred to as the upper and lower control limits. The points, the scope of which represents the process dispersion, are each measured based on the average and the standard deviation of the safety conformity data for each factor. The upper control limit is obtained by adding three times the standard deviation value to the $\mathrm{X}$ bar value. Also, the lower control limit is attained by subtracting three times the standard deviation value to the $\mathrm{X}$ bar value. For the factor "forklift driver", the standard deviation is obtained as follows. The formula for standard deviation is:

$$
\sigma=\sqrt{\left[(x-\bar{x})^{2}\right] / n}
$$

The computation of the $\mathrm{R}$ chart follows the same procedure as conducted for the $\mathrm{X}$ bar except that the mean is replaced with range (Table 1).

Step 3: Group data into segments, factors, and levels.

Step 4: Determine and analyze the levels in each factor. (Table 2a, Table 2b, Table 2c, Table 2d, and Table 2e).

Step 5: Develop an orthogonal array using Minitab 16 statistical software (with levels and factors as the determining parameters) (Table $3 \mathrm{a}$, Table $3 \mathrm{~b}$, Table $3 \mathrm{c}$, Table 3d, and Table 3e)

Table 1. Percentage conformity for all segments (Stockroom)

\begin{tabular}{|c|c|c|c|c|c|c|}
\hline A segment of bottling plant $\downarrow$ & \multicolumn{6}{|c|}{ Control chart variables } \\
\hline Stockroom & $\mathrm{X}$ bar & $\begin{array}{r}\mathrm{R} \\
\text { chart }\end{array}$ & $\begin{array}{l}\text { UCL } \\
\text { (R) }\end{array}$ & $\begin{array}{l}\text { LCL } \\
\text { (R) }\end{array}$ & $\begin{array}{r}\text { UCL } \\
(\mathrm{X} \text { bar })\end{array}$ & $\begin{array}{r}\text { LCL } \\
(\mathrm{X} \text { bar })\end{array}$ \\
\hline Forklift Drivers & 99.36 & 7.69 & 2.18 & 3.74 & 101.41 & 97.31 \\
\hline Sorters & 75.00 & 0.00 & 0.00 & 0.00 & 75.00 & 75.00 \\
\hline Rescuer & 100.00 & 0.00 & 0.00 & 0.00 & 100.00 & 100.00 \\
\hline Sugar Handlers & 97.92 & 25.00 & 7.08 & 12.15 & 104.57 & 91.27 \\
\hline Haulage Drivers & 92.39 & 13.04 & 3.69 & 6.34 & 95.86 & 88.92 \\
\hline Haulage Truck Mates & 94.69 & 4.54 & 1.28 & 2.21 & 95.90 & 93.49 \\
\hline Chip Neck Remover & 98.33 & 20.00 & 5.66 & 9.72 & 103.65 & 93.01 \\
\hline Extra Bottle Remover & 97.22 & 33.33 & 9.43 & 16.20 & 106.09 & 88.36 \\
\hline \multicolumn{7}{|l|}{ Manufacturing hallway } \\
\hline Sighters & 98.96 & 12.5 & 3.54 & 6.07 & 102.28 & 95.63 \\
\hline Filler Operator & 98.33 & 20.00 & 5.66 & 9.72 & 103.65 & 93.01 \\
\hline Palletizers/Depalletizer & 83.33 & 0.00 & 0 & 0.00 & 83.33 & 83.33 \\
\hline
\end{tabular}


S.A. Oke and I.O.Fagbolagun

Table 1. (continued)

\begin{tabular}{|c|c|c|c|c|c|c|}
\hline \multirow{2}{*}{$\frac{\text { A segment of bottling plant } \downarrow}{\text { Stockroom }}$} & \multicolumn{6}{|c|}{ Control chart variables } \\
\hline & $\mathrm{X}$ bar & $\begin{array}{c}\mathrm{R} \\
\text { chart }\end{array}$ & $\begin{array}{l}\text { UCL } \\
(\mathrm{R})\end{array}$ & $\begin{array}{l}\text { LCL } \\
(\mathrm{R})\end{array}$ & $\begin{array}{r}\text { UCL } \\
\text { (X bar) }\end{array}$ & $\begin{array}{r}\text { LCL } \\
\text { (X bar) }\end{array}$ \\
\hline Washer Operators & 93.75 & 50.00 & 14.15 & 24.30 & 107.05 & 80.45 \\
\hline Chip Neck Removers & 98.96 & 12.50 & 3.54 & 6.07 & 102.28 & 95.63 \\
\hline Technical Operators/Utilities & 100.00 & 0.00 & 0.00 & 0.00 & 100.00 & 100.00 \\
\hline Packer/Unpacker Operators & 100.00 & 0.00 & 0.00 & 0.00 & 100.00 & 100.00 \\
\hline \multicolumn{7}{|l|}{ Beverage testing unit } \\
\hline Sugar Lifters & 100.00 & 0.00 & 0.00 & 0.00 & 100.00 & 100.00 \\
\hline Syrup Mixers & 92.71 & 50.00 & 14.15 & 24.30 & 106.00 & 79.41 \\
\hline Lab Technicians & 84.72 & 16.67 & 4,72 & 8.10 & 89.15 & 80.28 \\
\hline Water Technicians & 91.67 & 50.00 & 14.15 & 24.30 & 104.97 & 78.37 \\
\hline ETP Technicians & 95.83 & 50.00 & 14.15 & 24.30 & 109.13 & 82.53 \\
\hline Others & 94.61 & 5.88 & 1.66 & 2.86 & 96.17 & 93.05 \\
\hline \multicolumn{7}{|l|}{ Shuttle vehicle flotilla } \\
\hline Forklift Technicians & 100.00 & 0.00 & 0.00 & 0.00 & 100.00 & 100.00 \\
\hline Welders & 91.67 & 100.00 & 28.30 & 48.59 & 118.27 & 65.07 \\
\hline Battery Charger/Technicians & 100.00 & 0.00 & 0.00 & 0.00 & 100.00 & 100.00 \\
\hline \multicolumn{7}{|l|}{ Suppliers } \\
\hline Security & 98.48 & 13.64 & 3.86 & 6.63 & 102.11 & 94.86 \\
\hline Kitchen & 98.61 & 8.33 & 2.36 & 4.05 & 100.83 & 96.40 \\
\hline Supplier 1 & 94.05 & 7.14 & 2.02 & 3.47 & 95.95 & 92.15 \\
\hline Supplier 2 & 97.83 & 13.04 & 3.69 & 6.34 & 101.30 & 94.36 \\
\hline Supplier 3 & 100.00 & 0.00 & 0.00 & 0.00 & 100.00 & 100.00 \\
\hline
\end{tabular}

Table 2a. Segments, factors, and levels. Segment 1 (stockroom 8 X 4)

\begin{tabular}{|l|l|c|c|}
\hline \multicolumn{1}{|c|}{ Factors } & Level 1 $(\mathrm{R})$ & $\begin{array}{c}\text { Level 2 } \\
\text { Average__R }\}\}\end{array}$ & $\begin{array}{c}\text { Level 3 } \\
\text { Average_\{X\}\} }\end{array}$ \\
\hline Forklift Drivers & 7.6900 & 2.9565 & 99.3592 \\
\hline Sorters & 0.0000 & 0.0000 & 75.0000 \\
\hline Rescuer & 0.0000 & 0.0000 & 100.0000 \\
\hline Sugar Handlers & 25.0000 & 9.6114 & 97.9167 \\
\hline Haulage Drivers & 13.0400 & 5.0133 & 92.3883 \\
\hline Haulage Truck Mates & 4.5400 & 1.7454 & 94.6933 \\
\hline Chip Neck Remover & 20.0000 & 7.6891 & 98.3333 \\
\hline Extra Bottle Remover & 33.3300 & 12.8139 & 97.2225 \\
\hline
\end{tabular}

Table 2b. Segments, factors and levels. Segment 2 (Manufacturing hallway 7 X 4)

\begin{tabular}{|l|l|c|c|}
\hline \multicolumn{1}{|c|}{ Factors } & Level 1 ( R ) & $\begin{array}{c}\text { Level 2 } \\
\text { Average_\{R\}\} }\end{array}$ & $\begin{array}{c}\text { Level 3 } \\
\text { Average_\{X\}\} }\end{array}$ \\
\hline Sighters & 12.5000 & 4.8057 & 98.9583 \\
\hline Filler Operator & 20.0000 & 7.6891 & 98.3333 \\
\hline Palletizers/Depalletizer & 0.0000 & 0.0000 & 83.3300 \\
\hline Washer Operators & 50.0000 & 19.2228 & 93.7500 \\
\hline Chip Neck Remover & 12.5000 & 4.8057 & 98.9583 \\
\hline Technical Operators/Utilities & 0.0000 & 0.0000 & 100.0000 \\
\hline Packer/Unpacker Operators & 0.0000 & 0.0000 & 100.0000 \\
\hline
\end{tabular}


Table 2c. Segments, factors and levels. Segment 3 (beverage testing unit 6 X 4)

\begin{tabular}{|l|l|c|c|}
\hline \multicolumn{1}{|c|}{ Factors } & Level 1 $(\mathrm{R})$ & $\begin{array}{c}\text { Level 2 } \\
\text { Average_\{R\}\} }\end{array}$ & $\begin{array}{c}\text { Level 3 } \\
\text { Average_\{X\}\} }\end{array}$ \\
\hline Sugar Lifters & 0.0000 & 0.0000 & 100.0000 \\
\hline Syrup Mixers & 50.0000 & 19.2228 & 92.7083 \\
\hline Lab Technicians & 16.6700 & 6.4089 & 84.7192 \\
\hline Water Technicians & 50.0000 & 19.2228 & 91.6667 \\
\hline ETP Technicians & 50.0000 & 19.2228 & 95.8333 \\
\hline Others & 5.8800 & 2.2606 & 94.6100 \\
\hline
\end{tabular}

Table 2d. Segments, factors and levels. Segment 4 (shuttle vehicle flotilla 3 X 4)

\begin{tabular}{|l|l|c|c|}
\hline \multicolumn{1}{|c|}{ Factors } & Level 1 $(\mathrm{R})$ & $\begin{array}{c}\text { Level 2 } \\
\text { Average__R }\}\}\end{array}$ & $\begin{array}{c}\text { Level 3 } \\
\text { Average__ }\{\mathrm{X}\}\}\end{array}$ \\
\hline Forklift Technicians & 0.0000 & 0.0000 & 100.0000 \\
\hline Welders & 100.0000 & 38.4456 & 91.6667 \\
\hline Battery Charger/Technicians & 0.0000 & 0.0000 & 100.0000 \\
\hline
\end{tabular}

Table 2e. Segments, factors and levels. Segment 5 (suppliers - Local 5 X 4)

\begin{tabular}{|l|l|c|c|}
\hline \multicolumn{1}{|c|}{ Factors } & Level 1 ( R ) & $\begin{array}{c}\text { Level 2 } \\
\text { Average_\{R\}\} }\end{array}$ & $\begin{array}{c}\text { Level 3 } \\
\text { Average_\{X\}\} }\end{array}$ \\
\hline Security & 13.6400 & 5.2440 & 98.4842 \\
\hline Kitchen & 8.3300 & 3.2025 & 98.6117 \\
\hline Supplier 1 & 7.1400 & 2.7450 & 94.0500 \\
\hline Supplier 2 & 13.0400 & 5.0133 & 97.8267 \\
\hline Supplier 3 & 0.0000 & 0.0000 & 100.0000 \\
\hline
\end{tabular}

Table 3a. Segment 1 (stockroom) L27 (3**8) Orthogonal Array

\begin{tabular}{|c|c|c|c|c|c|c|c|c|}
\hline $\mathrm{S} / \mathrm{N}$ & $\begin{array}{l}\text { Forklift } \\
\text { Drivers }\end{array}$ & Sorters & Rescuer & $\begin{array}{c}\text { Sugar } \\
\text { Handlers }\end{array}$ & $\begin{array}{l}\text { Haulage } \\
\text { Drivers }\end{array}$ & $\begin{array}{c}\text { Haulage } \\
\text { Truck Mates }\end{array}$ & $\begin{array}{l}\text { Chip Neck } \\
\text { Remover }\end{array}$ & $\begin{array}{c}\text { Extra Bottle } \\
\text { Remover }\end{array}$ \\
\hline 1 & 1 & 1 & 1 & 1 & 1 & 1 & 1 & 1 \\
\hline 2 & 1 & 1 & 1 & 1 & 2 & 2 & 2 & 2 \\
\hline 3 & 1 & 1 & 1 & 1 & 3 & 3 & 3 & 3 \\
\hline 4 & 1 & 2 & 2 & 2 & 1 & 1 & 1 & 2 \\
\hline 5 & 1 & 2 & 2 & 2 & 2 & 2 & 2 & 3 \\
\hline 6 & 1 & 2 & 2 & 2 & 3 & 3 & 3 & 1 \\
\hline 7 & 1 & 3 & 3 & 3 & 1 & 1 & 1 & 3 \\
\hline 8 & 1 & 3 & 3 & 3 & 2 & 2 & 2 & 1 \\
\hline 9 & 1 & 3 & 3 & 3 & 3 & 3 & 3 & 2 \\
\hline 10 & 2 & 1 & 2 & 3 & 1 & 2 & 3 & 1 \\
\hline 11 & 2 & 1 & 2 & 3 & 2 & 3 & 1 & 2 \\
\hline 12 & 2 & 1 & 2 & 3 & 3 & 1 & 2 & 3 \\
\hline 13 & 2 & 2 & 3 & 1 & 1 & 2 & 3 & 2 \\
\hline 14 & 2 & 2 & 3 & 1 & 2 & 3 & 1 & 3 \\
\hline 15 & 2 & 2 & 3 & 1 & 3 & 1 & 2 & 1 \\
\hline 16 & 2 & 3 & 1 & 2 & 1 & 2 & 3 & 3 \\
\hline 17 & 2 & 3 & 1 & 2 & 2 & 3 & 1 & 1 \\
\hline 18 & 2 & 3 & 1 & 2 & 3 & 1 & 2 & 2 \\
\hline 19 & 3 & 1 & 3 & 2 & 1 & 3 & 2 & 1 \\
\hline 20 & 3 & 1 & 3 & 2 & 2 & 1 & 3 & 2 \\
\hline 21 & 3 & 1 & 3 & 2 & 3 & 2 & 1 & 3 \\
\hline 22 & 3 & 2 & 1 & 3 & 1 & 3 & 2 & 2 \\
\hline
\end{tabular}


Table 3a. (continued)

\begin{tabular}{|c|c|c|c|c|c|c|c|c|}
\hline S/N & $\begin{array}{c}\text { Forklift } \\
\text { Drivers }\end{array}$ & Sorters & Rescuer & $\begin{array}{c}\text { Sugar } \\
\text { Handlers }\end{array}$ & $\begin{array}{c}\text { Haulage } \\
\text { Drivers }\end{array}$ & $\begin{array}{c}\text { Haulage } \\
\text { Truck Mates }\end{array}$ & $\begin{array}{c}\text { Chip Neck } \\
\text { Remover }\end{array}$ & $\begin{array}{c}\text { Extra Bottle } \\
\text { Remover }\end{array}$ \\
\hline 23 & 3 & 2 & 1 & 3 & 2 & 1 & 3 & 3 \\
\hline 24 & 3 & 2 & 1 & 3 & 3 & 2 & 1 & 1 \\
\hline 25 & 3 & 3 & 2 & 1 & 1 & 3 & 2 & 3 \\
\hline 26 & 3 & 3 & 2 & 1 & 2 & 1 & 3 & 1 \\
\hline 27 & 3 & 3 & 2 & 1 & 3 & 2 & 1 & 2 \\
\hline
\end{tabular}

Table 3b. Segment 2 (Manufacturing hallway) L27 (3**7) Orthogonal Array

\begin{tabular}{|c|c|c|c|c|c|c|c|}
\hline $\mathrm{S} / \mathrm{N}$ & Sighters & $\begin{array}{c}\text { Filler } \\
\text { Operator }\end{array}$ & $\begin{array}{l}\text { Palletizers/ } \\
\text { Depalletizer }\end{array}$ & $\begin{array}{l}\text { Washer } \\
\text { Operators }\end{array}$ & $\begin{array}{c}\text { Chip } \\
\text { Neck } \\
\text { Remover }\end{array}$ & $\begin{array}{c}\text { Technical } \\
\text { Operators/ } \\
\text { Utilities }\end{array}$ & $\begin{array}{l}\text { Packer/ } \\
\text { Unpacker } \\
\text { Operators }\end{array}$ \\
\hline 1 & 1 & 1 & 1 & 1 & 1 & 1 & 1 \\
\hline 2 & 1 & 1 & 1 & 1 & 2 & 2 & 2 \\
\hline 3 & 1 & 1 & 1 & 1 & 3 & 3 & 3 \\
\hline 4 & 1 & 2 & 2 & 2 & 1 & 1 & 1 \\
\hline 5 & 1 & 2 & 2 & 2 & 2 & 2 & 2 \\
\hline 6 & 1 & 2 & 2 & 2 & 3 & 3 & 3 \\
\hline 7 & 1 & 3 & 3 & 3 & 1 & 1 & 1 \\
\hline 8 & 1 & 3 & 3 & 3 & 2 & 2 & 2 \\
\hline 9 & 1 & 3 & 3 & 3 & 3 & 3 & 3 \\
\hline 10 & 2 & 1 & 2 & 3 & 1 & 2 & 3 \\
\hline 11 & 2 & 1 & 2 & 3 & 2 & 3 & 1 \\
\hline 12 & 2 & 1 & 2 & 3 & 3 & 1 & 2 \\
\hline 13 & 2 & 2 & 3 & 1 & 1 & 2 & 3 \\
\hline 14 & 2 & 2 & 3 & 1 & 2 & 3 & 1 \\
\hline 15 & 2 & 2 & 3 & 1 & 3 & 1 & 2 \\
\hline 16 & 2 & 3 & 1 & 2 & 1 & 2 & 3 \\
\hline 17 & 2 & 3 & 1 & 2 & 2 & 3 & 1 \\
\hline 18 & 2 & 3 & 1 & 2 & 3 & 1 & 2 \\
\hline 19 & 3 & 1 & 3 & 2 & 1 & 3 & 2 \\
\hline 20 & 3 & 1 & 3 & 2 & 2 & 1 & 3 \\
\hline 21 & 3 & 1 & 3 & 2 & 3 & 2 & 1 \\
\hline 22 & 3 & 2 & 1 & 3 & 1 & 3 & 2 \\
\hline 23 & 3 & 2 & 1 & 3 & 2 & 1 & 3 \\
\hline 24 & 3 & 2 & 1 & 3 & 3 & 2 & 1 \\
\hline 25 & 3 & 3 & 2 & 1 & 1 & 3 & 2 \\
\hline 26 & 3 & 3 & 2 & 1 & 2 & 1 & 3 \\
\hline 27 & 3 & 3 & 2 & 1 & 3 & 2 & 1 \\
\hline
\end{tabular}

Table 3c. Segment 3 (Beverage testing unit) L27(3**6) Orthogonal Array

\begin{tabular}{|c|c|c|c|c|c|c|}
\hline S/N & $\begin{array}{c}\text { Sugar } \\
\text { Lifters }\end{array}$ & $\begin{array}{c}\text { Syrup } \\
\text { Mixers }\end{array}$ & $\begin{array}{c}\text { Lab } \\
\text { Technicians }\end{array}$ & $\begin{array}{c}\text { Water } \\
\text { Technicians }\end{array}$ & $\begin{array}{c}\text { ETP } \\
\text { Technicians }\end{array}$ & Others \\
\hline 1 & 1 & 1 & 1 & 1 & 1 & 1 \\
\hline 2 & 1 & 1 & 1 & 1 & 2 & 2 \\
\hline 3 & 1 & 1 & 1 & 1 & 3 & 3 \\
\hline 4 & 1 & 2 & 2 & 2 & 1 & 1 \\
\hline 5 & 1 & 2 & 2 & 2 & 2 & 2 \\
\hline 6 & 1 & 2 & 2 & 2 & 3 & 3 \\
\hline 7 & 1 & 3 & 3 & 3 & 2 & 1 \\
\hline 8 & 1 & 3 & 3 & 3 & 3 & 3 \\
\hline 9 & 1 & 3 & 3 & 3 & & \\
\hline
\end{tabular}


Table 3c. (continued)

\begin{tabular}{|c|c|c|c|c|c|c|}
\hline $\mathrm{S} / \mathrm{N}$ & $\begin{array}{l}\text { Sugar } \\
\text { Lifters }\end{array}$ & $\begin{array}{l}\text { Syrup } \\
\text { Mixers }\end{array}$ & $\begin{array}{c}\text { Lab } \\
\text { Technicians }\end{array}$ & $\begin{array}{c}\text { Water } \\
\text { Technicians }\end{array}$ & $\begin{array}{c}\text { ETP } \\
\text { Technicians }\end{array}$ & Others \\
\hline 10 & 2 & 1 & 2 & 3 & 1 & 2 \\
\hline 11 & 2 & 1 & 2 & 3 & 2 & 3 \\
\hline 12 & 2 & 1 & 2 & 3 & 3 & 1 \\
\hline 13 & 2 & 2 & 3 & 1 & 1 & 2 \\
\hline 14 & 2 & 2 & 3 & 1 & 2 & 3 \\
\hline 15 & 2 & 2 & 3 & 1 & 3 & 1 \\
\hline 16 & 2 & 3 & 1 & 2 & 1 & 2 \\
\hline 17 & 2 & 3 & 1 & 2 & 2 & 3 \\
\hline 18 & 2 & 3 & 1 & 2 & 3 & 1 \\
\hline 19 & 3 & 1 & 3 & 2 & 1 & 3 \\
\hline 20 & 3 & 1 & 3 & 2 & 2 & 1 \\
\hline 21 & 3 & 1 & 3 & 2 & 3 & 2 \\
\hline 22 & 3 & 2 & 1 & 3 & 1 & 3 \\
\hline 23 & 3 & 2 & 1 & 3 & 2 & 1 \\
\hline 24 & 3 & 2 & 1 & 3 & 3 & 2 \\
\hline 25 & 3 & 3 & 2 & 1 & 1 & 3 \\
\hline 26 & 3 & 3 & 2 & 1 & 2 & 1 \\
\hline 27 & 3 & 3 & 2 & 1 & 3 & 2 \\
\hline
\end{tabular}

Table 3d. Segment 4 (shuttle vehicle flotilla) L9 (3**3) Orthogonal Array

\begin{tabular}{|r|c|c|c|}
\hline S/N & $\begin{array}{c}\text { Forklift } \\
\text { Technicians }\end{array}$ & Welders & $\begin{array}{c}\text { Battery } \\
\text { Charger/Technicians }\end{array}$ \\
\hline 1 & 1 & 1 & 1 \\
\hline 2 & 1 & 2 & 2 \\
\hline 3 & 1 & 3 & 3 \\
\hline 4 & 2 & 1 & 2 \\
\hline 5 & 2 & 2 & 3 \\
\hline 6 & 2 & 3 & 1 \\
\hline 7 & 3 & 1 & 3 \\
\hline 8 & 3 & 2 & 1 \\
\hline 9 & 3 & 3 & 2 \\
\hline
\end{tabular}

Table 3e. Segment 5 (suppliers - Local/Others) L27 (3**5) Orthogonal Array

\begin{tabular}{|r|c|c|c|c|c|}
\hline S/N & Security & Kitchen & Supplier 1 & Supplier 2 & Supplier 3 \\
\hline 1 & 1 & 1 & 1 & 1 & 1 \\
\hline 2 & 1 & 1 & 1 & 1 & 2 \\
\hline 3 & 1 & 1 & 1 & 1 & 3 \\
\hline 4 & 1 & 2 & 2 & 2 & 1 \\
\hline 5 & 1 & 2 & 2 & 2 & 2 \\
\hline 6 & 1 & 2 & 2 & 2 & 3 \\
\hline 7 & 1 & 3 & 3 & 3 & 1 \\
\hline 8 & 1 & 3 & 3 & 3 & 2 \\
\hline 9 & 1 & 3 & 3 & 3 & 3 \\
\hline 10 & 2 & 1 & 2 & 3 & 1 \\
\hline 11 & 2 & 1 & 2 & 3 & 2 \\
\hline 12 & 2 & 1 & 2 & 3 & 3 \\
\hline 13 & 2 & 2 & 3 & 1 & 1 \\
\hline 14 & 2 & 2 & 3 & 1 & 2 \\
\hline 15 & 2 & 2 & 3 & 1 & 3 \\
\hline 16 & 2 & 3 & 1 & 2 & 1 \\
\hline
\end{tabular}


Table 3e. (continued)

\begin{tabular}{|c|c|c|c|c|c|}
\hline S/N & Security & Kitchen & Supplier 1 & Supplier 2 & Supplier 3 \\
\hline 17 & 2 & 3 & 1 & 2 & 2 \\
\hline 18 & 2 & 3 & 1 & 2 & 3 \\
\hline 19 & 3 & 1 & 3 & 2 & 1 \\
\hline 20 & 3 & 1 & 3 & 2 & 2 \\
\hline 21 & 3 & 1 & 3 & 2 & 3 \\
\hline 22 & 3 & 2 & 1 & 3 & 1 \\
\hline 23 & 3 & 2 & 1 & 3 & 2 \\
\hline 24 & 3 & 2 & 1 & 3 & 3 \\
\hline 25 & 3 & 3 & 2 & 1 & 1 \\
\hline 26 & 3 & 3 & 2 & 1 & 2 \\
\hline 27 & 3 & 3 & 2 & 1 & 3 \\
\hline
\end{tabular}

In the study conformity process in a bottling plant, it is not frequent and proper to use a single work-group category to describe the safety conformity condition of the plant at any time field measurements are to be taken. Instead, to attain a full description of the safety conformity in the workplace, all the work-groups within all segments of the bottling process plant are combined and treated as parameters that need to be controlled and optimized. Field data were collected and analyzed by control charts ( $\mathrm{X}$ bar and $\mathrm{R}$ chart) and the Taguchi technique. Taguchi technique is created to Genichi Taguchi. The framework assumes a statistical nature as it strives to lessen changes in the bottling process in an idea called the design of experiments (Manjunath et al., 2017). While pursuing the use of the Taguchi method in this work, the driving force was to attain the utmost safety conformity outcome with reduced experiments (Manjunath et al., 2017). Manjunath et al. (2017) declared the orthogonal array as the principal strength of the Taguchi technique that works on the mechanism of controlling multiple factors concurrently such that information is extracted from all the factors at once and processed according to the defined levels of the factors to obtain the signal-to-noise quotient in the Taguchi analysis. As further declared by Manjunath (2017), the orthogonal array has competence in being able to appraise any of the parameters independent of one another. Thus, with this strength of orthogonal array, problematic parameters or those that give strength to the system, promoting the efficiency of the safety conformity process, can be ascertained.

Arising from the preliminary study, the input parameters for the different segments of the bottling plant were defined. Taguchi method, in this sense, was applied to establish which of these inputs are the most influential on the system. As such, the Taguchi scheme permits an opportunity to identify the low and highperforming parameters according to the values generated from the procedure. In this instance, it becomes easy to identify what groups within the segments always comply with the safety regulations and what groups do not, and how much they vary in performance. For the stockroom, the input parameters selected were forklift drivers, sorters, rescuers, sugar handlers, haulage drivers, haulage truck mates, chip neck removers, and extra bottle removers. In the case of the manufacturing hallway, the selected parameters were: sighters, filler operators, chip neck removers, technical operators/utilities, and packer/unpacker operators. The selected parameters for the beverage testing unit were syrup mixers, laboratory technicians, water technicians, ETP technicians, and others. For the vehicle fleet flotilla group, the selected parameters were the welders and security. The chosen parameters for suppliers are the kitchen, contractors 1 and 2. The array of input parameters together with their levels are revealed in Tables $2 \mathrm{a}, 2 \mathrm{~b}, 2 \mathrm{c}, 2 \mathrm{~d}$, and $2 \mathrm{e}$. In this work, two principal tools employed to analyze the Taguchi method are (i) $\mathrm{S} / \mathrm{N}$ quotients to evaluate the responses and (ii) orthogonal arrays to contain the several factors influencing the safety conformity concurrently to appraise the bottling process by performance.

Regarding the Taguchi quality design idea (Bobbili and Madhu, 2016), a parameter investigation by Taguchi L27(3**8) orthogonal array with 27 rows (experiments) was applied to study the integrated control chartTaguchi method, selected for the experiments in the stockroom (Table 3a) where three levels were considered for each parameter. An L27(3**7) orthogonal array with 27 experiments was applied to understand the integrated control chart-Taguchi method, selected for the experiments in the manufacturing hallway (Table 3b). Three levels were taken for each parameter. An L27(3**6) orthogonal array with 27 experiments was applied to understand the integrated control chart-Taguchi method, selected for the experiments in the beverage testing unit (Table 3c), where three levels were taken for each parameter. An L9 $(3 * * 3)$ orthogonal array with nine experiments was applied to understand the integrated control chartTaguchi method, selected for the experiments in the shuttle vehicle flotilla (Table 3d), where three levels were taken for each parameter. An L27 (3**5) orthogonal array with 27 experiments was applied understand the integrated control chart-Taguchi method, selected for the experiments in the suppliers-Local/ 
Others (Table 3e) where three levels were taken for each parameter.

In the current research, Minitab 16 statistical software was displayed to create the orthogonal designs, main effects plots, and analysis. In this research, diverse $\mathrm{S} / \mathrm{N}$ quotients were obtained, and each is associated with the segment of interest. The computations of these $\mathrm{S} / \mathrm{N}$ quotients were made with a choice from three $\mathrm{S} / \mathrm{N}$ quotient criteria: smaller-the-better, higher-the-better, and the nominal-the-best. However, in safety conformity assessment, it is desired that the employees attain the utmost safety conformity. The higher-thebetter criterion was chosen to analyze all the segments considered in this work.

The X-bar and R-chart motivated Taguchi method has to do with the infusion of X-bar and R-chart into Taguchi. Values for X-bar and R-chart were calculated, and these values were grouped into three levels. This was done for all segments. The levels and the corresponding factor were then used to get the orthogonal array, which in turn was used to obtain the signal to noise ratio, signal to noise response table, and the optimal parametric setting. The number of factors in each segment, in this case, remains the same as in previous cases as the same segment was being treated.

1) Segment 1, stockroom, had forklift driver with 19.41 as the factor with the most optimal parametric setting in level 1, chip neck remover and rescuer with 17.87 as the factors with the most optimal parametric setting in level 2, and haulage truck mate with 22.19 as the factor with the most optimal parametric setting in level 3 .

2) The specific optimized value derived was 0.6667 , that is, $66.67 \%$.

3) Segment 2, Manufacturing hallway, was evaluated and discovered to have packer/unpacker operators as the factor with the most optimal parametric setting with a value of 25.59 at level 1, level 2 has palletizer/depalletizer as the factor with the most optimal parametric setting at 24.62, chip neck remover at 27.12 is the factor with the most optimized parametric setting in level 3.

4) The specific optimal value for this segment remains 0.6667 , the same as that in the first segment, which is $66.67 \%$.
5) Segment 3, also known as the beverage testing unit segment, consists of six (6) factors, which seem to be the segment with the least value for the specific optimal value. It was grouped into three levels. The factor with the most optimal parametric setting at level 1 remains sugar lifters at 22.61 , water technicians at level 2 with a value of 21.27 , and 'Others' at level 3 with a figure of 28.75 .

6) The specific optimal value for the beverage testing unit was found to be 0.376 , which is about $37.6 \%$.

7) Field workshop, which is the fourth segment in the industry, has welders as the factor with the most optimal parametric setting in both level 1 and level 3 with a value of 43.18 and 42.25 , respectively. For level 2, the factor found to have the most optimal parametric setting is forklift technician at 41.55 .

8) The specific optimal value for this sector is calculated to be the same as that of segment 1 and 3, $66.67 \%$.

9) Segment 5, which is the segment that has to do with suppliers, comprises five factors. This segment was also grouped into three levels, with security as the factor with the most optimal parametric setting in level 1 , having a value of 20.81. supplier 3 with 17.8895 remains the factor with the highest value for optimal parametric setting in level2, while supplier 1 with 21.5236 is that for segment 3 .

10) The specific optimal value for this segment is also 0.6667 , which can be written in percentage as $66.67 \%$.

11) All the specific optimal values are the same save that of segment 3 .

Step 6: Substitute the actual values for the levels into the orthogonal array (Table 4a, Table 4b, Table 4c, Table $4 \mathrm{~d}$, and Table 4e)

Step 7: Generate the signal to noise response table (using the average of the signal to noise ratio at every level). (Table 5a, Table 5b, Table 5c, Table 5d, Table 5e)

Step 8: Get the optimal parametric setting from the signal to a noise response table.

Table 4a. Segment 1 (stockroom) L27 (3**8) Orthogonal Array

\begin{tabular}{|c|c|c|c|c|c|c|c|c|c|}
\hline S/N & $\begin{array}{c}\text { Forklift } \\
\text { Drivers }\end{array}$ & Sorters & Rescuer & $\begin{array}{c}\text { Sugar } \\
\text { Handlers }\end{array}$ & $\begin{array}{c}\text { Haulage } \\
\text { Drivers }\end{array}$ & $\begin{array}{c}\text { Haulage } \\
\text { Truck } \\
\text { Mates }\end{array}$ & $\begin{array}{c}\text { Chip Neck } \\
\text { Remover }\end{array}$ & $\begin{array}{c}\text { Extra } \\
\text { Bottle } \\
\text { Remover }\end{array}$ & $\begin{array}{c}\text { S/N( }(\eta) \\
\end{array}$ \\
\hline 1 & 7.69 & 0 & 0 & 25 & 13.04 & 4.54 & 20 & 33.33 & 0.00 \\
\hline 2 & 7.69 & 0 & 0 & 25 & 5.0133 & 1.7454 & 7.6891 & 12.8139 & 0.00 \\
\hline 3 & 7.69 & 0 & 0 & 25 & 92.3883 & 94.6933 & 98.3333 & 97.2225 & 0.00 \\
\hline 4 & 7.69 & 0 & 0 & 9.6114 & 13.04 & 4.54 & 20 & 12.8139 & 0.00 \\
\hline 5 & 7.69 & 0 & 0 & 9.6114 & 5.0133 & 1.7454 & 7.6891 & 97.2225 & 0.00 \\
\hline 6 & 7.69 & 0 & 0 & 9.6114 & 92.3883 & 94.6933 & 98.3333 & 33.33 & 0.00 \\
\hline 7 & 7.69 & 75 & 100 & 97.9167 & 13.04 & 4.54 & 20 & 97.2225 & 20.32 \\
\hline
\end{tabular}


S.A. Oke and I.O.Fagbolagun

Table 4a. (continued)

\begin{tabular}{|c|c|c|c|c|c|c|c|c|c|}
\hline S/N & $\begin{array}{c}\text { Forklift } \\
\text { Drivers }\end{array}$ & Sorters & Rescuer & $\begin{array}{c}\text { Sugar } \\
\text { Handlers }\end{array}$ & $\begin{array}{c}\text { Haulage } \\
\text { Drivers }\end{array}$ & $\begin{array}{c}\text { Haulage } \\
\text { Truck } \\
\text { Mates }\end{array}$ & $\begin{array}{c}\text { Chip Neck } \\
\text { Remover }\end{array}$ & $\begin{array}{c}\text { Extra } \\
\text { Bottle } \\
\text { Remover }\end{array}$ & $\mathrm{S} / \mathrm{N}(\eta)$ \\
\hline 8 & 7.69 & 75 & 100 & 97.9167 & 5.0133 & 1.7454 & 7.6891 & 33.33 & 12.98 \\
\hline 9 & 7.69 & 75 & 100 & 97.9167 & 92.3883 & 94.6933 & 98.3333 & 12.8139 & 25.28 \\
\hline 10 & 2.9565 & 0 & 0 & 97.9167 & 13.04 & 1.7454 & 98.3333 & 33.33 & 0.00 \\
\hline 11 & 2.9565 & 0 & 0 & 97.9167 & 5.0133 & 94.6933 & 20 & 12.8139 & 0.00 \\
\hline 12 & 2.9565 & 0 & 0 & 97.9167 & 92.3883 & 4.54 & 7.6891 & 97.2225 & 0.00 \\
\hline 13 & 2.9565 & 0 & 100 & 25 & 13.04 & 1.7454 & 98.3333 & 12.8139 & 0.00 \\
\hline 14 & 2.9565 & 0 & 100 & 25 & 5.0133 & 94.6933 & 20 & 97.2225 & 0.00 \\
\hline 15 & 2.9565 & 0 & 100 & 25 & 92.3883 & 4.54 & 7.6891 & 33.33 & 0.00 \\
\hline 16 & 2.9565 & 75 & 0 & 9.6114 & 13.04 & 1.7454 & 98.3333 & 97.2225 & 0.00 \\
\hline 17 & 2.9565 & 75 & 0 & 9.6114 & 5.0133 & 94.6933 & 20 & 33.33 & 0.00 \\
\hline 18 & 2.9565 & 75 & 0 & 9.6114 & 92.3883 & 4.54 & 7.6891 & 12.8139 & 0.00 \\
\hline 19 & 99.3592 & 0 & 100 & 9.6114 & 13.04 & 94.6933 & 7.6891 & 33.33 & 0.00 \\
\hline 20 & 99.3592 & 0 & 100 & 9.6114 & 5.0133 & 4.54 & 98.3333 & 12.8139 & 0.00 \\
\hline 21 & 99.3592 & 0 & 100 & 9.6114 & 92.3883 & 1.7454 & 20 & 97.2225 & 0.00 \\
\hline 22 & 99.3592 & 0 & 0 & 97.9167 & 13.04 & 94.6933 & 7.6891 & 12.8139 & 0.00 \\
\hline 23 & 99.3592 & 0 & 0 & 97.9167 & 5.0133 & 4.54 & 98.3333 & 97.2225 & 0.00 \\
\hline 24 & 99.3592 & 0 & 0 & 97.9167 & 92.3883 & 1.7454 & 20 & 33.33 & 0.00 \\
\hline 25 & 99.3592 & 75 & 0 & 25 & 13.04 & 94.6933 & 7.6891 & 97.2225 & 0.00 \\
\hline 26 & 99.3592 & 75 & 0 & 25 & 5.0133 & 4.54 & 98.3333 & 33.33 & 0.00 \\
\hline 27 & 99.3592 & 75 & 0 & 25 & 92.3883 & 1.7454 & 20 & 12.8139 & 0.00 \\
\hline
\end{tabular}

Table 4b. Segment 2 (Manufacturing Hallway) L27 (3**7) Orthogonal Array

\begin{tabular}{|c|c|c|c|c|c|c|c|c|}
\hline S/N & Sighters & $\begin{array}{c}\text { Filler } \\
\text { Operator }\end{array}$ & $\begin{array}{c}\text { Palletizers/ } \\
\text { Depalletizer }\end{array}$ & $\begin{array}{c}\text { Washer } \\
\text { Operators }\end{array}$ & $\begin{array}{c}\text { Chip Neck } \\
\text { Remover }\end{array}$ & $\begin{array}{c}\text { Technical } \\
\text { Operators/ } \\
\text { Utilities }\end{array}$ & $\begin{array}{c}\text { Packer/ } \\
\text { Unpacker } \\
\text { Operators }\end{array}$ & $\mathrm{S} / \mathrm{N}(\eta)$ \\
\hline 1 & 12.5 & 20 & 0 & 50 & 12.5 & 0 & 0 & 0.00 \\
\hline 2 & 12.5 & 20 & 0 & 50 & 4.8057 & 0 & 0 & 0.00 \\
\hline 3 & 12.5 & 20 & 0 & 50 & 98.9583 & 100 & 100 & 0.00 \\
\hline 4 & 12.5 & 7.689 & 0 & 19.2228 & 12.5 & 0 & 0 & 0.00 \\
\hline 5 & 12.5 & 7.689 & 0 & 19.2228 & 4.8057 & 0 & 0 & 0.00 \\
\hline 6 & 12.5 & 7.689 & 0 & 19.2228 & 98.9583 & 100 & 100 & 0.00 \\
\hline 7 & 12.5 & 98.33 & 83.33 & 93.75 & 12.5 & 0 & 0 & 0.00 \\
\hline 8 & 12.5 & 98.33 & 83.33 & 93.75 & 4.8057 & 0 & 0 & 0.00 \\
\hline 9 & 12.5 & 98.33 & 83.33 & 93.75 & 98.9583 & 100 & 100 & 29.96 \\
\hline 10 & 4.8057 & 20 & 0 & 93.75 & 12.5 & 0 & 100 & 0.00 \\
\hline 11 & 4.8057 & 20 & 0 & 93.75 & 4.8057 & 100 & 0 & 0.00 \\
\hline 12 & 4.8057 & 20 & 0 & 93.75 & 98.9583 & 0 & 0 & 0.00 \\
\hline 13 & 4.8057 & 7.689 & 83.33 & 50 & 12.5 & 0 & 100 & 0.00 \\
\hline 14 & 4.8057 & 7.689 & 83.33 & 50 & 4.8057 & 100 & 0 & 0.00 \\
\hline 15 & 4.8057 & 7.689 & 83.33 & 50 & 98.9583 & 0 & 0 & 0.00 \\
\hline 16 & 4.8057 & 98.33 & 0 & 19.2228 & 12.5 & 0 & 100 & 0.00 \\
\hline 17 & 4.8057 & 98.33 & 0 & 19.2228 & 4.8057 & 100 & 0 & 0.00 \\
\hline 18 & 4.8057 & 98.33 & 0 & 19.2228 & 98.9583 & 0 & 0 & 0.00 \\
\hline 19 & 98.9583 & 20 & 83.33 & 19.2228 & 12.5 & 100 & 0 & 0.00 \\
\hline 20 & 98.9583 & 20 & 83.33 & 19.2228 & 4.8057 & 0 & 100 & 0.00 \\
\hline 21 & 98.9583 & 20 & 83.33 & 19.2228 & 98.9583 & 0 & 0 & 0.00 \\
\hline 22 & 98.9583 & 7.689 & 0 & 93.75 & 12.5 & 100 & 0 & 0.00 \\
\hline 23 & 98.9583 & 7.689 & 0 & 93.75 & 4.8057 & 0 & 100 & 0.00 \\
\hline 24 & 98.9583 & 7.689 & 0 & 93.75 & 98.9583 & 0 & 0 & 0.00 \\
\hline 25 & 98.9583 & 98.33 & 0 & 50 & 12.5 & 100 & 0 & 0.00 \\
\hline 26 & 98.9583 & 98.33 & 0 & 50 & 4.8057 & 0 & 100 & 0.00 \\
\hline 27 & 98.9583 & 98.33 & 0 & 50 & 98.9583 & 0 & 0 & 0.00 \\
\hline & & & & & & & & \\
\hline
\end{tabular}


Table 4c. Segment 3 (beverage testing unit) L27(3**6) Orthogonal Array

\begin{tabular}{|c|c|c|c|c|c|c|c|}
\hline $\mathrm{S} / \mathrm{N}$ & $\begin{array}{c}\text { Sugar } \\
\text { Lifters }\end{array}$ & $\begin{array}{l}\text { Syrup } \\
\text { Mixers }\end{array}$ & $\begin{array}{c}\text { Lab } \\
\text { Technicians }\end{array}$ & $\begin{array}{c}\text { Water } \\
\text { Technicians }\end{array}$ & $\begin{array}{c}\text { ETP } \\
\text { Technicians }\end{array}$ & Others & $\mathrm{S} / \mathrm{N}(\eta)$ \\
\hline 1 & 0 & 50 & 16.67 & 50 & 50 & 5.88 & 0.00 \\
\hline 2 & 0 & 50 & 16.67 & 50 & 19.2228 & 2.2606 & 0.00 \\
\hline 3 & 0 & 50 & 16.67 & 50 & 95.8333 & 94.61 & 0.00 \\
\hline 4 & 0 & 19.22 & 6.4089 & 19.2228 & 50 & 5.88 & 0.00 \\
\hline 5 & 0 & 19.22 & 6.4089 & 19.2228 & 19.2228 & 2.2606 & 0.00 \\
\hline 6 & 0 & 19.22 & 6.4089 & 19.2228 & 95.8333 & 94.61 & 0.00 \\
\hline 7 & 0 & 92.71 & 84.7192 & 91.6667 & 50 & 5.88 & 0.00 \\
\hline 8 & 0 & 92.71 & 84.7192 & 91.6667 & 19.2228 & 2.2606 & 0.00 \\
\hline 9 & 0 & 92.71 & 84.7192 & 91.6667 & 95.8333 & 94.61 & 0.00 \\
\hline 10 & 0 & 50 & 6.4089 & 91.6667 & 50 & 2.2606 & 0.00 \\
\hline 11 & 0 & 50 & 6.4089 & 91.6667 & 19.2228 & 94.61 & 0.00 \\
\hline 12 & 0 & 50 & 6.4089 & 91.6667 & 95.8333 & 5.88 & 0.00 \\
\hline 13 & 0 & 19.22 & 84.7192 & 50 & 50 & 2.2606 & 0.00 \\
\hline 14 & 0 & 19.22 & 84.7192 & 50 & 19.2228 & 94.61 & 0.00 \\
\hline 15 & 0 & 19.22 & 84.7192 & 50 & 95.8333 & 5.88 & 0.00 \\
\hline 16 & 0 & 92.71 & 16.67 & 19.2228 & 50 & 2.2606 & 0.00 \\
\hline 17 & 0 & 92.71 & 16.67 & 19.2228 & 19.2228 & 94.61 & 0.00 \\
\hline 18 & 0 & 92.71 & 16.67 & 19.2228 & 95.8333 & 5.88 & 0.00 \\
\hline 19 & 100 & 50 & 84.7192 & 19.2228 & 50 & 94.61 & 31.92 \\
\hline 20 & 100 & 50 & 84.7192 & 19.2228 & 19.2228 & 5.88 & 22.34 \\
\hline 21 & 100 & 50 & 84.7192 & 19.2228 & 95.8333 & 2.2606 & 14.79 \\
\hline 22 & 100 & 19.22 & 16.67 & 91.6667 & 50 & 94.61 & 29.31 \\
\hline 23 & 100 & 19.22 & 16.67 & 91.6667 & 19.2228 & 5.88 & 21.97 \\
\hline 24 & 100 & 19.22 & 16.67 & 91.6667 & 95.8333 & 2.2606 & 14.72 \\
\hline 25 & 100 & 92.71 & 6.4089 & 50 & 50 & 94.61 & 23.72 \\
\hline 26 & 100 & 92.71 & 6.4089 & 50 & 19.2228 & 5.88 & 20.25 \\
\hline 27 & 100 & 92.71 & 6.4089 & 50 & 95.8333 & 2.2606 & 14.34 \\
\hline
\end{tabular}

Table 4d. Segment 4 (shuttle vehicle flotilla) L9 (3**3) Orthogonal Array

\begin{tabular}{|c|c|c|c|c|}
\hline S/N & $\begin{array}{c}\text { Forklift } \\
\text { Technicians }\end{array}$ & Welders & $\begin{array}{c}\text { Battery } \\
\text { Charger/ } \\
\text { Technicians }\end{array}$ & $\mathrm{S} / \mathrm{N}(\eta)$ \\
\hline 1 & 0 & 100 & 0 & 0.00 \\
\hline 2 & 0 & 38.45 & 0 & 0.00 \\
\hline 3 & 0 & 91.6667 & 100 & 0.00 \\
\hline 4 & 0 & 100 & 0 & 0.00 \\
\hline 5 & 0 & 38.45 & 100 & 0.00 \\
\hline 6 & 0 & 91.6667 & 0 & 0.00 \\
\hline 7 & 100 & 100 & 100 & 43.01 \\
\hline 8 & 100 & 38.45 & 0 & 0.00 \\
\hline 9 & 100 & 91.6667 & 0 & 0.00 \\
\hline
\end{tabular}

Table 4e. Segment 5 (suppliers - Local/Others) L27 (3**5) Orthogonal Array

\begin{tabular}{|c|c|c|c|c|c|c|}
\hline S/N & Security & Kitchen & Supplier 1 & Supplier 2 & Supplier 3 & S/N( $)$ \\
\hline 1 & 13.64 & 8.33 & 7.14 & 13.04 & 0 & 0.00 \\
\hline 2 & 13.64 & 8.33 & 7.14 & 13.04 & 0 & 21.22 \\
\hline 3 & 13.64 & 8.33 & 7.14 & 13.04 & 100 & 21.22 \\
\hline 4 & 13.64 & 3.2025 & 2.745 & 5.0133 & 0 & 0.00 \\
\hline 5 & 13.64 & 3.2025 & 2.745 & 5.0133 & 0 & 13.38 \\
\hline 6 & 13.64 & 3.2025 & 2.745 & 5.0133 & 100 & 13.38 \\
\hline
\end{tabular}


S.A. Oke and I.O.Fagbolagun

Table 4e. (continued)

\begin{tabular}{|c|c|c|c|c|c|c|}
\hline $\mathrm{S} / \mathrm{N}$ & Security & Kitchen & Supplier 1 & Supplier 2 & Supplier 3 & $\mathrm{~S} / \mathrm{N}(\eta)$ \\
\hline 7 & 13.64 & 98.612 & 94.05 & 97.8267 & 0 & 0.00 \\
\hline 8 & 13.64 & 98.612 & 94.05 & 97.8267 & 0 & 30.48 \\
\hline 9 & 13.64 & 98.612 & 94.05 & 97.8267 & 100 & 30.48 \\
\hline 10 & 5.244 & 8.33 & 2.745 & 97.8267 & 0 & 0.00 \\
\hline 11 & 5.244 & 8.33 & 2.745 & 97.8267 & 0 & 15.15 \\
\hline 12 & 5.244 & 8.33 & 2.745 & 97.8267 & 100 & 15.15 \\
\hline 13 & 5.244 & 3.2025 & 94.05 & 13.04 & 0 & 0.00 \\
\hline 14 & 5.244 & 3.2025 & 94.05 & 13.04 & 0 & 16.33 \\
\hline 15 & 5.244 & 3.2025 & 94.05 & 13.04 & 100 & 16.33 \\
\hline 16 & 5.244 & 98.612 & 7.14 & 5.0133 & 0 & 0.00 \\
\hline 17 & 5.244 & 98.612 & 7.14 & 5.0133 & 0 & 17.97 \\
\hline 18 & 5.244 & 98.612 & 7.14 & 5.0133 & 100 & 17.97 \\
\hline 19 & 98.4842 & 8.33 & 94.05 & 5.0133 & 0 & 0.00 \\
\hline 20 & 98.4842 & 8.33 & 94.05 & 5.0133 & 0 & 20.43 \\
\hline 21 & 98.4842 & 8.33 & 94.05 & 5.0133 & 100 & 20.43 \\
\hline 22 & 98.4842 & 3.2025 & 7.14 & 97.8267 & 0 & 0.00 \\
\hline 23 & 98.4842 & 3.2025 & 7.14 & 97.8267 & 0 & 17.09 \\
\hline 24 & 98.4842 & 3.2025 & 7.14 & 97.8267 & 100 & 17.09 \\
\hline 25 & 98.4842 & 98.612 & 2.745 & 13.04 & 0 & 0.00 \\
\hline 26 & 98.4842 & 98.612 & 2.745 & 13.04 & 0 & 16.36 \\
\hline 27 & 98.4842 & 98.612 & 2.745 & 13.04 & 100 & 16.36 \\
\hline
\end{tabular}

Table 5a. Signal-To-Noise Response Table. Segment 1 (stockroom)

\begin{tabular}{|c|c|c|c|c|c|c|c|c|}
\hline Level & $\begin{array}{c}\text { Forklift } \\
\text { Drivers }\end{array}$ & Sorters & Rescuer & $\begin{array}{c}\text { Sugar } \\
\text { Handlers }\end{array}$ & $\begin{array}{c}\text { Haulage } \\
\text { Drivers }\end{array}$ & $\begin{array}{c}\text { Haulage } \\
\text { Truck Mates }\end{array}$ & $\begin{array}{c}\text { Chip Neck } \\
\text { Remover }\end{array}$ & $\begin{array}{c}\text { Extra Bottle } \\
\text { Remover }\end{array}$ \\
\hline 1 & 6.51 & 0.00 & 0.00 & 0.00 & 2.81 & 2.81 & 2.81 & 2.81 \\
\hline 2 & 0.00 & 0.00 & 0.00 & 0.00 & 2.81 & 2.81 & 2.81 & 2.81 \\
\hline 3 & 0.00 & 6.51 & 6.51 & 6.51 & 2.81 & 2.81 & 2.81 & 2.81 \\
\hline
\end{tabular}

Table 5b. Signal-To-Noise Response Table. Segment 2 (Manufacturing hallway)

\begin{tabular}{|c|c|c|c|c|c|c|c|}
\hline Level & Sighters & $\begin{array}{c}\text { Filler } \\
\text { Operator }\end{array}$ & $\begin{array}{c}\text { Palletizers } \\
\text { /Depalletizer }\end{array}$ & $\begin{array}{c}\text { Washer } \\
\text { Operators }\end{array}$ & $\begin{array}{c}\text { Chip Neck } \\
\text { Remover }\end{array}$ & $\begin{array}{c}\text { Technical } \\
\text { Operators } \\
\text { /Utilities }\end{array}$ & $\begin{array}{c}\text { Packer/ } \\
\text { Unpacker } \\
\text { Operators }\end{array}$ \\
\hline 1 & 3.33 & 0.00 & 0.00 & 0.00 & 0.00 & 0.00 & 0.00 \\
\hline 2 & 0.00 & 0.00 & 0.00 & 0.00 & 0.00 & 0.00 & 0.00 \\
\hline 3 & 0.00 & 3.33 & 3.33 & 3.33 & 3.33 & 3.33 & 3.33 \\
\hline
\end{tabular}

Table 5c. Signal-To-Noise Response Table. Segment 3 (beverage testing unit)

\begin{tabular}{|c|c|c|c|c|c|c|}
\hline Level & $\begin{array}{c}\text { Sugar } \\
\text { Lifters }\end{array}$ & $\begin{array}{c}\text { Syrup } \\
\text { Mixers }\end{array}$ & $\begin{array}{c}\text { Lab } \\
\text { Technicians }\end{array}$ & $\begin{array}{c}\text { Water } \\
\text { Technicians }\end{array}$ & $\begin{array}{c}\text { ETP } \\
\text { Technicians }\end{array}$ & Others \\
\hline 1 & 0.00 & 7.67 & 7.33 & 6.48 & 9.44 & 8.07 \\
\hline 2 & 0.00 & 7.33 & 6.48 & 7.67 & 7.17 & 4.87 \\
\hline 3 & 21.49 & 6.48 & 7.67 & 7.33 & 4.87 & 9.44 \\
\hline
\end{tabular}

Table 5d. Signal-To-Noise Response Table. Segment 4 (shuttle vehicle flotilla)

\begin{tabular}{|c|c|c|c|}
\hline Level & $\begin{array}{c}\text { Forklift } \\
\text { Technicians }\end{array}$ & Welders & $\begin{array}{c}\text { Battery } \\
\text { Charger/Technicians }\end{array}$ \\
\hline 1 & 40.87 & 43.18 & 41.55 \\
\hline 2 & 41.55 & 36.07 & 40.87 \\
\hline 3 & 39.08 & 42.25 & 39.08 \\
\hline
\end{tabular}


Table 5e. Signal-To-Noise Response Table. Segment 5 (suppliers - Local/Others)

\begin{tabular}{|c|c|c|c|c|c|}
\hline Level & Security & Kitchen & Supplier 1 & Supplier 2 & Supplier 3 \\
\hline 1 & 20.81 & 18.14 & 17.96 & 17.17 & 17.89 \\
\hline 2 & 15.68 & 14.81 & 14.17 & 16.46 & 17.88954 \\
\hline 3 & 17.16 & 20.71514 & 21.5236 & 20.01805 & 17.87715 \\
\hline
\end{tabular}

Step 9 : Get the optimal parametric setting from the signal to a noise response table.

Optimal Parametric Setting

This is the highest value gotten from the signal to noise response table for each level. That is the factor with the highest level in each level.

1) Segment 1 (stockroom): The optimal parametric setting for level $1\left(\mathrm{~A}_{1} \mathrm{FD}\right)$, level $2\left(\mathrm{~A}_{2} \mathrm{CNR}\right)$ and level $3\left(\mathrm{~A}_{3} \mathrm{HTM}\right)$ are $19.41,17.87$ and 22.19 , respectively.

2) Segment 2 (Manufacturing hallway): The optimal parametric setting for level 1 ( $\left.\mathrm{A}_{1} \mathrm{PUO}\right)$, level 2 $\left(\mathrm{A}_{2} \mathrm{PD}\right)$, and level $3\left(\mathrm{~A}_{3} \mathrm{CNR}\right)$ are $25.59,24.62$, and 27.12 , respectively.

3) Segment 3 (beverage testing unit): The optimal parametric setting for level $1\left(\mathrm{~A}_{1} \mathrm{SL}\right)$, level 2 $\left(\mathrm{A}_{2} \mathrm{WT}\right)$, and level $3\left(\mathrm{~A}_{3} \mathrm{O}\right)$ are $22.61,21.27$, and 28.95 , respectively.

4) Segment 4 (shuttle vehicle flotilla): The optimal parametric setting for level $1(\mathrm{~A} 1 \mathrm{~W})$, level $2\left(\mathrm{~A}_{2} \mathrm{FT}\right)$, and level $3\left(\mathrm{~A}_{3} \mathrm{~W}\right)$ are 43.18, 41.55, and 42.25, respectively.

5) Segment 5 (suppliers - Local/Others): The optimal parametric setting level $1\left(\mathrm{~A}_{1} \mathrm{~S}\right)$, level $2\left(\mathrm{~A}_{2} \mathrm{C}_{3}\right)$ and level $3\left(\mathrm{~A}_{3} \mathrm{C}_{1}\right)$ are 20.81, 17.90, and 21.52, respectively.

Step 10: Calculate the optimized global value. Global Optimized Value

The normalization of the Optimal Parametric Setting is known as the Global Optimized Value

$\eta=($ Current level - Minimum level $) /($ Maximum level - Minimum level)

- $\quad$ Segment 1 (stockroom): $\eta 1, \eta 2$ and $\eta 3$ are $0.36,0$ and 1 , respectively.

- $\quad$ Segment 2 (Manufacturing hallway): $\eta 1, \eta 2$, and $\eta 3$ are $0.39,0$, and 1 , respectively.

- $\quad$ Segment 3 (Beverage testing unit): $\eta 1, \eta 2$, and $\eta 3$ are $0.17,0$, and 1 , respectively.

- $\quad$ Segment 4 (shuttle vehicle flotilla): $\eta 1, \eta 2$, and $n 3$ are 1,0 , and 0.43 , respectively.

- $\quad$ Segment 5 (suppliers - Local/Others): $れ 1, \eta 2$ and $\eta 3$ are $0.80,0$ and 1 , respectively.

Step 11: Calculate the specific optimized value (i.e., the average of optimized global value).

Specific Optimized Value

The average is calculated for the Global Optimized Value to get the Specific Optimized Value. $(\eta=(\eta 1+$ $n 2+n 3) / 3)$
- $\quad$ Segment 1 (stockroom): $\Pi$ is 0.666667

- Segment 2 (Manufacturing hallway): $\Pi$ is 0.666667

- Segment 3 (Beverage testing unit): $\prod$ is 0.376

- Segment 4 (shuttle vehicle flotilla): $\prod$ is 0.666667

- Segment 5 (suppliers - Local/Others): $\Pi$ is 0.666667

Data were obtained from all segments in the bottling plant to obtain the conformity index of the industrial workers in the industry in adherence to safety guidelines in the industry. The data was computed using the X-bar and R-chart motivated Taguchi method. X-bar and Rchart motivated Taguchi method has to do with the infusion of X-bar and R-chart into Taguchi. Values for $\mathrm{x}$-bar and $\mathrm{R}$ were calculated, and these values were grouped into three levels. This was done for all segments. The levels and the corresponding factor were then used to get the orthogonal array, which in turn was used to obtain the signal to noise ratio, signal to noise response table, and the optimal parametric setting. The number of factors in each segment, in this case, remains the same as in previous cases as the same segment was being treated. Segment 1, stockroom, had forklift driver with 19.41 as the factor with the most optimal parametric setting in level 1 , chip neck remover and rescuer with 17.87 as the factors with the most optimal parametric setting in level 2, and haulage truck mate with 22.19 as the factor with the most optimal parametric setting in level 3. The specific optimized value derived was 0.6667 , that is, $66.67 \%$. Segment 2, Manufacturing hallway, was evaluated and discovered to have packer/unpacker operators as the factor with the most optimal parametric setting with a value of 25.59 at level 1, level 2 has palletizer/depalletizer as the factor with the most optimal parametric setting at 24.62, chip neck remover at 27.12 is the factor with the most optimized parametric setting in level 3.

The specific optimal value for this segment remains 0.6667 , the same as that in the first segment, $66.67 \%$. Segment 3, also known as the beverage testing unit segment, consisting of six factors, seems to be the segment with the least value for the specific optimal value. It was grouped into three levels. The factor with the most optimal parametric setting at level 1 remains sugar lifters at 22.61, water technicians at level 2 with a value of 21.27, and 'Others' at level 3 with a figure of 28.75. The specific optimal value for the beverage testing unit was found to be 0.376 , which is about $37.6 \%$. Field workshop, which is the fourth (4th) segment in the industry, has welders as the factor with the most optimal parametric setting in both level 1 and level 3 with a value of 43.18 and 42.25 , respectively. For 
level 2, the factor found to have the most optimal parametric setting is forklift technician at 41.55 . The specific optimal value for this sector is calculated to be the same as that of segment 1 and 3, 66.67\%.

Segment 5, which is the segment that has to do with suppliers, comprises five (5) factors. This segment was also grouped into three levels, with security as the factor with the most optimal parametric setting in level 1, having a value of 20.81. supplier 3 with 17.8895 remains the factor with the highest value for optimal parametric setting in level2, while supplier 1 with 21.5236 is that for segment 3. The specific optimal value for this segment is also 0.6667, which can be written in percentage as $66.67 \%$. All the specific optimal values are the same save that of segment 3 .

In Taguchi analysis, the signal-to-noise ratio has a very important role in fulfilling the methodology's purpose. The larger, the better option was used due to the fact that the issue was being discussed in a desirable one. Comparing the average signal to noise ratio of each segment, it can be seen that the average signal to noise ratio was observed to be highest in Segment 4 (shuttle vehicle flotilla) with a total average signal to noise ratio of 40.50. It is followed by Segment 2 (Manufacturing hallway) with a total average signal-to-noise ratio of 22.86; segment 3 (beverage testing unit) had an average of 21.76. The segment with the least average signal to noise ratio is Segment 5 (suppliers - Local/Others), with an average of 17.89, followed by Segment 1 (stockroom), with an average of 18.73.'Haulage Drivers' was the factor with the least average signal to noise ratio in the bottling plant, as it had 17.49, as the average signal to noise ratio for levels 1,2 , and 3, followed closely by 'Rescuer', with 17.84 as the average signal to noise ratio for level 1, 2 and 3 . The factors with utmost average signal to noise ratio for each segment are forklift technicians, welders, and Battery charger/technicians for segment 4 (shuttle vehicle flotilla) at 40.50, Sighters, Filler Operator, Palletizers/Depalletizer, Chip Neck Remover, and Packer/Unpacker Operators for Segment 2 (Manufacturing hallway), Haulage Truck Mates for segment 1 (stockroom) at 22.19. All factors had the exact value of the signal-to-noise ratio for Segment 3 (beverage testing unit) and Segment 5 (suppliers Local/Others) at 21.76 and 17.89 , respectively. The average signal-to-noise ratio of workers in segment 1 is that the stockroom is lower than segment 2, which is, manufacturing hallway, with 4.13 . The average signalto-noise ratio of workers in segment 1 , that is, stockroom, compared to segment 3 , which is the beverage testing unit, is lower with about 3.03. When compared with segment 4 (shuttle vehicle flotilla), the average signal-to-noise ratio of segment 1 , that is, stockroom, was found to be lower with 21.77.

Comparing segment 1 , that is, stockroom, with segment 5 (suppliers - local/others) revealed that the average signal to noise ratio of segment 1 was higher by about 0.85 than that of segment 5.Comparing segment two and segment 3, that is, Manufacturing hallway and beverage testing unit, revealed the average signal to noise ratio of workers in segment two higher with 1.10 than the average signal to noise ratio of workers in segment 3 . When compared with segment 4 (shuttle vehicle flotilla), the average signal-to-noise ratio of workers in the Manufacturing hallway, that is, segment 2, was found to be lower with a decrease of 17.64 than that of segment 4 , that is, shuttle vehicle flotilla. The average signal-to-noise ratio of workers in segment 2, that is, the Manufacturing hallway, is higher, compared to segment 5 (suppliers - local/others) with 4.98 . The average signal-to-noise ratio of the workers in segment 3 , beverage testing unit, compared to segment 4 , that is, shuttle vehicle flotilla, was lower with 18.74. The same comparison was done between segment 3, that is, beverage testing unit, and segment 5 (supplier local/others), and it was discovered that segment 3, beverage testing unit, had a higher average signal to noise ratio of 3.88 than segment 5 (suppliers local/others).

The average signal to noise ratio of workers in segment 4, that is, shuttle vehicle flotilla, when compared to segment 5 (suppliers - local/others), showed that segment 4 , that is, shuttle vehicle flotilla when compared to suppliers (local/others) is higher with about 22.61. The specific optimized value of workers in segment 1, that is, stockroom, when compared to segment 2, which is, Manufacturing hallway, was found to be the same. The specific optimized value of workers in segment 1 , that is, stockroom, compared to segment 3 , which is the beverage testing unit, is higher with about 0.2907 . When compared with segment 4 (shuttle vehicle flotilla), the specific optimized value of segment 1 , that is, stockroom, was found to be the same as 0.6667 . Comparing segment 1 , that is, stockroom, with segment 5 (suppliers - local/others) revealed that the specific optimized value of segment five was found to be the same as that of segment 1.Comparing segment two and segment 3, that is, Manufacturing hallway and beverage testing unit, revealed the specific optimized value of workers in segment two higher with about 0.2907 than the specific optimized value of workers in segment 3 . When compared with segment 4 (shuttle vehicle flotilla), the specific optimized value of workers in Manufacturing hallway, that is, segment 2, no difference was found with that of segment 4 , that is, shuttle vehicle flotilla, which is 0.6667 . The specific optimized value of workers in segment two, the Manufacturing hallway, is the same, compared to segment 5 (suppliers local/others) with 0.2431 . The specific optimized value of the workers in segment 3, beverage testing unit, compared to segment 4 , that is, shuttle vehicle flotilla, was lower with 0.2907 . The same comparison was done between segment 3 , that is, beverage testing unit and segment 5 (suppliers - local/others), and it was discovered that segment 3 , beverage testing unit, had a lower specific optimized value of 0.2907 to segment 5 (suppliers - local/others). The specific optimized value of workers in segment 4 , that is, shuttle vehicle flotilla, compared to segment 5 (suppliers - local/others), showed that segment 4 , that is, shuttle vehicle flotilla when compared to suppliers (local/others), is same. 


\section{NOVELTY OF THE ARTICLE, LIMITATIONS, AND FUTURE STUDIES}

\subsection{Novelty and impact of the article in an industrial society}

Soft drinks, which are manufactured globally in different packaging and flavors, are available in noteworthy quantities from villages to major cities. These villages and cities are an industrial society run by soft drinks bottling technology in the context of mass production. The large population is supported with various skill management in the bottling plant. In such an environment, evading injuries to humans and damage to equipment is critical to increasing the profits, reducing expenses, gaining more confidence of the workers, making workers more comfortable and focused, and reducing job absenteeism.

In recent times, as a result of high product demands from soft drinks production, the equipment manning capacity and the level of experience required from the workers have changed. More workers are given various functions to implement, ranging from activities in the stockroom to manufacturing hallway, to beverage testing unit, to shuttle vehicles flotilla and suppliers. Thus, there is a need for a clear way of ensuring a high level of safety quality control and optimizing conformance activities in all the segments of the bottling process plant. This will be used by the safety manager so that the organization can work effectively and produce high-quality bottled drinks for customers. Stakeholders are interested in the bottling plant's safety conformity level, but there is no clearly defined approach to sharing this information with the stakeholders. Consequently, the present authors intend to implement a framework on the $\mathrm{X}$ bar and $\mathrm{R}$ chart element of a quality control system associated with safety conformity and concurrently optimizing the outcome of the process.

In this context, the development of a joint framework using the control charts and Taguchi optimization scheme is the novelty of the present article. The work will assist safety managers in gaining additional understanding of the safety conformity assessment and how it can be applied in an industrial society. The following is a summary of the novelty of this article:

- A new alternative to the multiple-regression method named the CCTM is proposed for the safety conformity control and optimization problem in a bottling process plant; and

- Integrating control chart principles and the Taguchi scheme into the evaluation system. The solution to the problem has been presented to monitor changes in the conformity index over time and minimizing it, using the two approaches of control chart (X bar and $\mathrm{R}$ chart) and Taguchi scheme.

\subsection{Limitations and future studies}

Future studies can enhance and develop this research from diverse perspectives. First, the quantification of the number of conforming workers to safety guidelines and rules used here was based on the fact that the same employees participated in the safety conformity assessment over the period of data collection. Indeed, some kinds of systemic changes take place such that the same individuals may not have been assessed during the data collection period. Employee turnover, employee absenteeism, reposting, and all forms of activities that displace the employee from the job assigned to him/her initially could affect the quantified safety conformity values. However, this study has no contact with this kind of data. Another path of future studies may be to build up and re-define the fundamental model. This research attached substantial utility to the control and optimization aspects of the model. However, scholars could gainfully search for substantial details concerning the interrelationships of the prioritization concept with the current model.

The Taguchi-Pareto model with the ability to capture the prioritization of factors can replace the Taguchi method. The combination of benefits attained from the new model will be the concurrent control, optimization, and prioritization of safety conformity factors. Additional studies could bring forward its scope to incorporate economic issues that may particularly enlighten the research community considering that cost management is central to safety budget planning and implementation in the bottling plant. Furthermore, in the future, the system's state as a whole, whether in a healthy state or otherwise, with respect to safety conformity should be judged. The introduction of a performance flow diagram that instantly declares the status of the system may be helpful. The idea is to treat each factor as a distinct element that occupies a point on the number scale, determined by the position attained during the optimal parametric setting of the Taguchi method. So, an overall value, which may be positive or negative, could be obtained. It should specify a healthy state for the positive values and an unhealthy state for the negative values. Furthermore, it should depend on the concept of the beneficial and non-beneficial influence of the factors on the response.

\section{CONCLUSION}

The inbuilt benefits of the control charts should contribute to the enlarged use of the $\mathrm{X}$ bar and the $\mathrm{R}$ chart control tools by safety researchers since it permits them to study factory workers in a bottling plant and establish whether the workers are working within or outside the control of the expected behavior and safety culture by using safety kits themselves and machine part covers as protective devices against direct access to moving parts that could cause harm, accidents or even loss of lives of the workers. 
The main conclusions of the work are as follows:

1. The use of the hybrid control chart-Taguchi method is feasible to evaluate the safety conformity for the bottling process plant studied and aided the workers' adherence to the set guidelines for safety.

2. The optimal value using the Taguchi method while control charts are embedded into it yielded comparatively higher values than for the Taguchi method alone

\section{REFERENCES}

Abdellah, A., Noordin, M.I., \& Ismail, W.A.W. (2015). Importance and globalization status of good manufacturing practice (GMP) requirements for pharmaceutical excipients. Saudi Pharmaceutical Journal, 23(1), 9-13.

Alhrathi, A.A., \& Yang, Q. (2014). Application of Taguchi method in health and safety fire extinguishing experiment. International Journal of Engineering Research and Applications, 4(5), 37-44.

Ansary, M.A., \& Barna, U. (2015). Workplace compliance of RMG industry in Bangladesh: Structural assessment of RMG factory buildings. International Journal of Disaster Risk Reduction, 14, 424-437.

Ayomoh, M.K.O., \& Oke, S.A. (2006). A framework for measuring safety levels for production environments. Safety Science, 44, 221-239.

Azadeh, A., \& Sheikhalishahi, M. (2015). An efficient Taguchi approach for the performance optimization of health, safety, environment, and ergonomics in generation companies. Safety and Health at Work, $6(2), 77-84$.

Baldissone, G., Comberti, L., Bosca, S., \& Murè, S. (2019). The analysis and management of unsafe acts and unsafe conditions: Data collection and analysis. Safety Science, 119, 240-251.

Bobbili, R., \& Madhu, V. (2016). Sliding mean behaviour of E-glass-epoxy/MWCNT composites: An experimental assessment. Engineering Science and Technology, an International Journal, 19(1), 8-14.

Brhlikova, P., Harper, I., Subedi, M., Bhattarai, S., Rawal, N., \& Pollock, A.M. (2015). Aid conditionalities, international good manufacturing practice standards, and local production rights: a case study of local production in Nepal. Global Health, 11(25), 1-10.

Cheng, S.Y., Lin, K.P., Liou, Y.W., Hsiao, C.H., \& Liu, Y.J. (2019). Constructing an active health and safety performance questionnaire in the food manufacturing industry. International Journal of Occupational Safety and Ergonomics, 27(2), 1-21.
Dźwiarek, M., \& Latała, A. (2016). Analysis of occupational accidents: prevention through the use of additional technical safety measures for machinery. International Journal of Occupational Safety and Ergonomics, 22(2), 186-192.

Diaz, Y.F., \& Resmick, M.L. (2000). A model to predict employee compliance with employee corporate's safety regulations factoring risk perception. Proceedings of the Human Factors and Ergonomics Society Annual Meeting, 44(27), 323-326.

Geraci, C.L., Tinkle, S.S., Brenner, S.A., Hodson, L.L., Pomeroy-Carter, C.A., \& Neu-Baker, N. (2018). Launching the dialogue: Safety and innovation as partners for success in advanced manufacturing. Journal of Occupational and Environmental Hygiene, 15(6), D45-D50.

Gressgard, L.J. (2014). Knowledge management and safety compliance in a high-risk distributed organisation system. Safety and Health at Work, 5, 5359.

Grob, K., Stocker, J., \& Colwell, R. (2009). Assurance of compliance within the production chain of food contact materials by good manufacturing practice and documentation - Part 1: Legal background in Europe and compliance challenges. Food Control, 20(5), 476482.

Grob, K., \& Marmiroli, G. (2009). Assurance of compliance within the production chain of food contact materials by good manufacturing practice and documentation - Part 3: Lids for glass jars as an example. Food Control, 20(5), 491-500.

Hong, C.C., Ramayah, T., \& Subramaniam, C. (2018). The relationship between critical success factors, internal control, and safety performance in the Malaysian manufacturing sector. Safety Science, 104 179-188.

Kalashnikov, A., \& Sakrutina, E. (2019). Safety management system and significant plants of critical information infrastructure. IFAC-PapersOnLine, 52(13), 1391-1396.

Landi, L., Amici, D., Boldrini, O.A., \& Germani, E. (2018). Sheets impact simulation for safety guards design: experiments and correlation for FE Explicit models of non-alloy steel. Procedia Structural Integrity, 8, 3-13.

Li, F., Jiang, L., Yao, X., \& Li, Y. (2013). Job demands, job resources, and safety outcomes: The role of emotional exhaustion and safety compliance. Accident Analysis and Prevention, 51, 243-251.

Lüken, K., Pardon, H., \& Windemuth, D. (2006). Bypassing and defeating protective devices of machines - a multidimensional problem. INRS Hygiene et securite du travail, 4(205), 55-58. 
Mewes, D., Mewes, O., \& Herbst, P. (2011). Impact resistance of guards on grinding machines. International Journal of Occupational Safety and Ergonomics, 17(4), 411-421.

Martins, S.A., \& Oke, S.A. (2020). Safety conformity prediction for a bottling process plant: using multiple regression analysis for enhanced safety performance, Kufa Journal of Engineering, 11(2), 28-48.

Manjunath, G.B., Bharath, K, N., Ganesh, D.B., Rajkamar, D.G., Shivprakash, P., \& Harsha, H.M. (2017). ANOVA and response surface methodology for the optimization of fracture toughness parameters on jute fabric-epoxy composites using SENB specimens. Materials Today: Proceedings, 4, 1128511291.

Oke, S.A., Johnson A.O., \& Omogoroye O.O. (2005). A neurofuzzy theoretic approach to safety control at crude oil exploration platforms. Disaster Prevention and Management: An International Journal, 14(4), 454-461.

Oke, S.A., Charles-Owaba, O.E., Johnson, A.O., \& Omogoroye, O.O. (2006). A fuzzy safety control framework for oil platforms. International Journal of Quality and Reliability Management, 23(5), 564-582.

Parker, D.L., Yamin, S.C., Brosseau, L.M., Xi, M., Gordon, R., Most, I.G., \& Stanley, R. (2015a). National machine guarding program: Part 1, Machine safe-guarding practices in small metal fabrication businesses. American Journal of Industrial Medicine, $58,1174-1183$.

Parker, D.L., Yamin, S.C., Brosseau, L.M., Xi, M., Gordon, R., Most, I.G., \& Stanley, R. (2015b). National machine guarding program: Part 2. Safety management in small metal fabrication enterprises. American Journal of Industrial Medicine, 58, 11841193.

Papic, L., \& Pantelic, M., (2014). Maintenance oriented safety control charts, International Journal of System Assurance Engineering and Management, 5(2), 149154.

Pichard, R., Philippot, A., \& Riera, B. (2017). Consistency checking of safety constraints for manufacturing systems with graph analysis. IFAC
Proceedings, 50(1), 1193-1198.

Riera, B., Coupat, R., Philippot, A., Annebique, D., \& Gellot, F. (2014). Control design pattern based on safety logical constraints for manufacturing systems: application to a palletizer, IFAC Proceedings, 47(2), 388-393.

Ruff, T.I., Coleman, P., \& Martini, L., (2011). Machinerelated injuries in the US mining industry and priorities for safety research. International Journal of Injury Control and Safety Promotion, 18(1), 11-20.

Schuh-Renner, A., Camelio, J., \& Woodall, W.H. (2013). Control charts for accident frequency: A motivation for real-time occupational safety monitoring. International Journal of Injury Control and Safety Promotion, 21(2).

Sii, H.S., Ruxton, T. \& Wang, J. (2001). Taguchi concepts and their applications in marine and offshore safety studies. Journal of Engineering Design, 12(4), 331-358.

Uzor, U., \& Oke, S.A., (2018). A model to predict and optimize machine guarding operator compliance activities in a bottling process plant: A developing country experience. International Journal of Occupational Safety and Ergonomics, 26(9), 1-37.

Vukicevic, A.M., Djapan, M., Stefanovic, M., \& Macuzic, I. (2019). SafE-Tag mobile: A novel javascript framework for real-time management of unsafe conditions and unsafe acts in SMEs. Safety Science, 120, 507-516.

Wikner, J., Hedvall, L., \& Mattsson, S.A. (2019). Hierarchical adaptive control of safety buffers in manufacturing. IFAC-PapersOnLine, 52(13), 26262631.

Yamin, S., Parker, D., Brosseau, L., Gordon, B., \& Xi, M. (2014). National machine guarding program: Design of a machine safety intervention. Safety Science Monitor, 18(1), 1-11.

Zin, S.M., \& Ismail, F. (2012). Employers' behavioural safety compliance factors towards occupational safety and health improvement in the construction industry. Procedia Social and Behavioural Sciences, 36, 742 751. 
This page is intentionally left blank 